\title{
MEASURING SHALLOW WATER WAVES
}

WITH PRESSURE SENSORS

\author{
Vitor Manuel Henriques Goncalo
}





\section{NAVAL POSTGRADUATE SCHOOL Monterey, California}
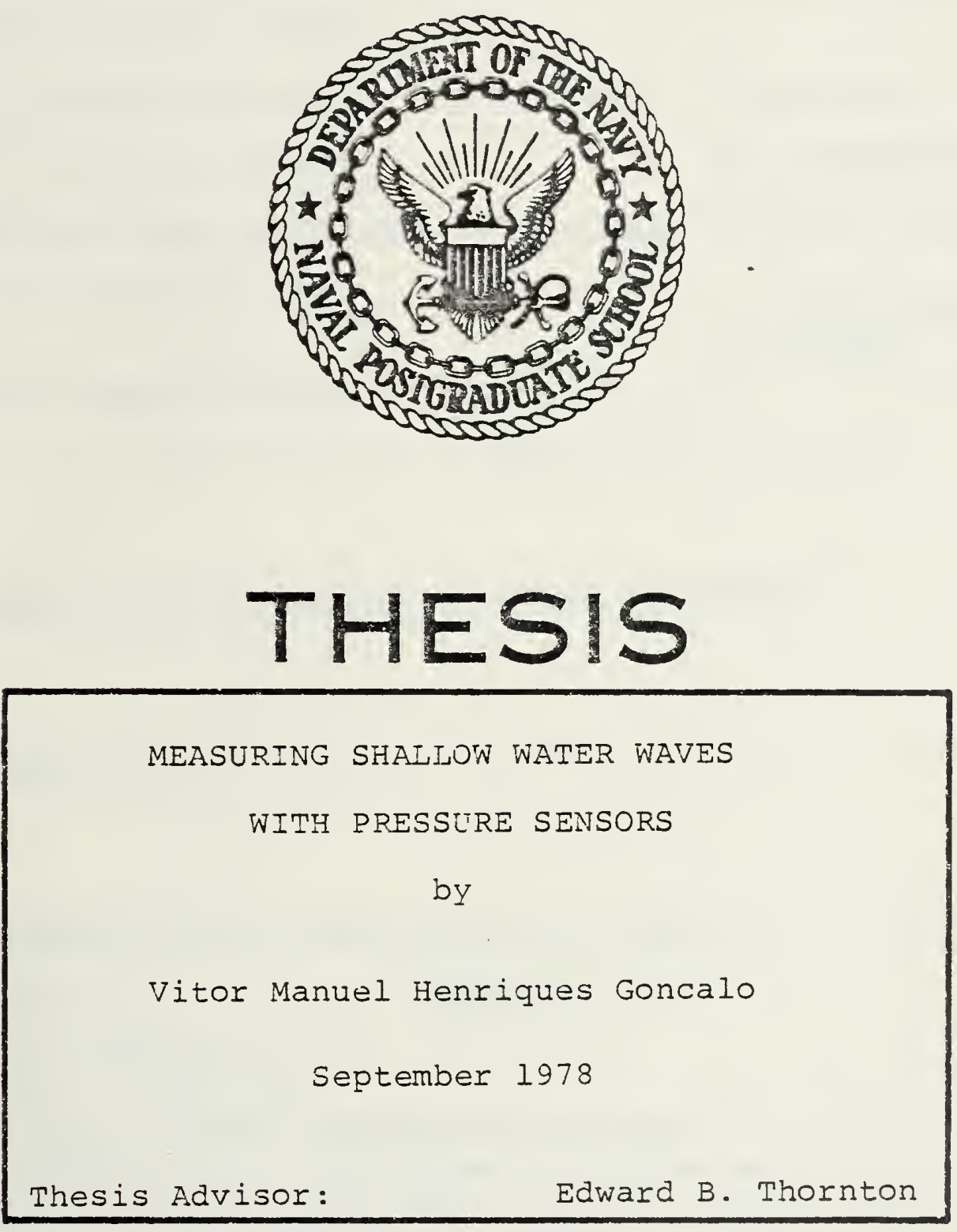

Approved for public release; distribution unlimited 



\begin{tabular}{|c|c|}
\hline REPORT DOCUMENTATION PAGE & $\begin{array}{c}\text { READ INSTRUCTINNS } \\
\text { BEFORE COMPLETING FORM } \\
\end{array}$ \\
\hline \begin{tabular}{l|l|} 
1. REPORT NUMBER & 2. GOVT ACCESSION NO. \\
\end{tabular} & 3. RECIPIENT'S CATALOG NUMBER \\
\hline \multirow[t]{2}{*}{$\begin{array}{l}\text { 4ITLE (and Subtrlo) } \\
\text { MEASUR ING SHALLOW WATER WAVES WITH } \\
\text { PRESSURE SENSORS }\end{array}$} & $\begin{array}{l}\text { 3. TYPE OF AEPORT A PEAIOO COVEREO } \\
\text { Master'S Thes is } \\
\text { September } 1978\end{array}$ \\
\hline & 6. PERFORMING ORG. REPORT NUMBER \\
\hline $\begin{array}{l}\text { 7. AuTHod(") } \\
\text { Vitor Manuel Henriques Goncalo }\end{array}$ & 8. CONTRACT OR GRANT NLMBER(O) \\
\hline $\begin{array}{l}\text { 9. PERFORMING ORGANIZATION NAME AND AODRESS } \\
\text { Naval Postgraduate School } \\
\text { Monterey, California } 93940\end{array}$ & $\begin{array}{l}\text { 10. PROGRAM ELEMENT.PROJECT. TASK } \\
\text { AREA A WORK UNIT NUMBERS. }\end{array}$ \\
\hline 11. CONTROLLING OFFICE NAME ANO ADORESS & 12. REPORT DATE \\
\hline $\begin{array}{l}\text { Naval Postgraduate School } \\
\text { Monterey, California } 93940\end{array}$ & $\begin{array}{l}\text { September } 1978 \\
\text { 13. NUMBER OF PAGES } \\
66\end{array}$ \\
\hline $\begin{array}{l}\text { 14. MONITORING AGENCY NAME AOORESS(ll dillorent from Controlline Ollleo) } \\
\text { Naval Postgraduate School } \\
\text { Monterey, California } 93940\end{array}$ & $\begin{array}{l}\text { 15. SECUAITY CLASS. (Ol thlo POPORt) } \\
\text { UnClassified } \\
\end{array}$ \\
\hline & $\begin{array}{l}\text { 15. DECLASSIFICATION/DOWNGRADING } \\
\text { SCHEDULE }\end{array}$ \\
\hline
\end{tabular}

Approved for public release; distribution unlimited

17. DISTRIBUTION STATEMENT (of the abotfact entored in Block 20, $l$ dillorent troen Raport)

18. SUPPLEMENTARY NOTES

19. KEY WOAOS (Conilnue on pereree elde If neceecery and identlty by block number)

wave staff

pressure sensor

water particle velocity

orthogonal components
Bernoulli equation

flowmeters

20. ABSTAACT (Contimue on peverae otde 1 neceecery and ldentlfy by block number)

For two locations within the surf zone sea surface elevations were observed using a wave staff and a pressure sensor while simultaneously the two horizontal orthogonal components, $u$ and $v$, of water particle velocity were measured.

Surface elevations derived from pressure sensors are lower, mainly in the region of the crest, compared with the same surface elevations measured with wave gages. Pressure records are more smoothed than wave gage records, and the energy computed for wayes 

measured with a pressure sensor is consistently smaller than for waves measured with a wave gage.

Methods for converting pressure to surface elevation are given which include the non-linear velocity term $\left(u^{2}+v^{2}\right)$ which is usually neglected in the Bernoulli equation. Two techniques are proposed to include this term: 1) flowmeters are used to measure $u$ and $v$, and 2) the Bernoulli term is derived by determining the velocities by convolving the pressure records using a weighting function determined from shallow water theory.

The first technique gave improvements on the order of $3.4 \%$ to $7.8 \%$ of the total variance of the wave gage spectrum, whereas the second technique gave improvements on the order of $3.1 \%$ to 9.7\%. The improvements in both cases are approximately the same, with the second technique having the advantage of requiring only a pressure transducer. 

Approved for public release; distribution unlimited.

MEASURING SHALLOW WATER WAVES WITH PRESSURE SENSORS by

Vitor Manuel Henriques Goncalo
Lieutenant, Portuguese Navy

Submitted in partial fulfillment of the requirements for the degree of

MASTER OF SCIENCE IN METEOROLOGY AND OCEANOGRAPHY

from the

NAVAL POSTGRADUATE SCHOOL

September 1978 



\section{ABSTRACT}

For two locations within the surf zone sea surface elevations were observed using a wave staff and a pressure sensor while simultaneously the two horizontal orthogonal components, $u$ and $v$, of water particle velocity were measured.

Surface elevations derived from pressure sensors are lower, mainly in the region of the crest, compared with the same surface elevations measured with wave gages. Pressure records are more smoothed than wave gage records, and the energy computed for waves measured with a pressure sensor is consistently smaller than for waves measured with a wave gage.

Methods for converting pressure to surface elevation are given which include the non-linear velocity term $\left(u^{2}+v^{2}\right)$ which is usually neglected in the Bernoulli equation. Two techniques are proposed to include this term: 1) flowmeters are used to measure $u$ and $v$, and 2) the Bernoulli term is derived by determining the velocities by convolving the pressure records using a weighting function determined from shallow water theory.

The first technique gave improvements on the order of $3.4 \%$ to $7.8 \%$ of the total variance of the wave gage spectrum, whereas the second technique gave improvements on the order of $3.1 \%$ to $9.7 \%$. The improvements in both cases are approximately the same, with the second technique having the advantage of requiring only a pressure transducer. 

TABLE OF CONTENTS

I. INTRODUCTION-D--

A. HISTORICAI PERSPECTIVE-_-

B. OBJECTIVE--

II. MEASUREMENTS-----

A. EXPERIMENT SITES-- -

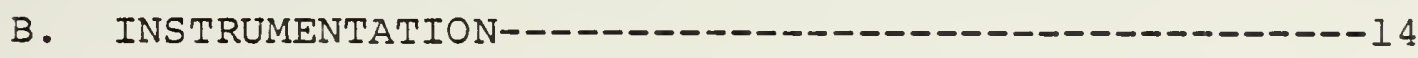

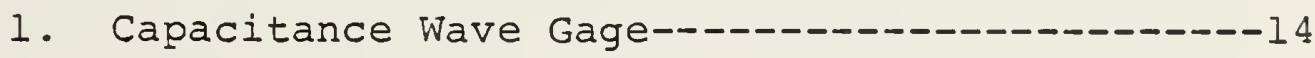

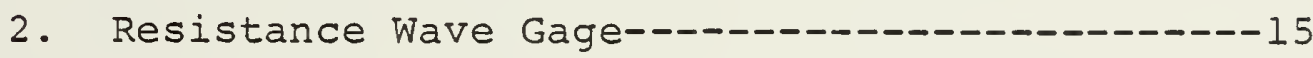

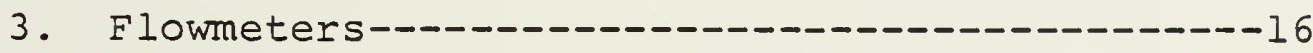

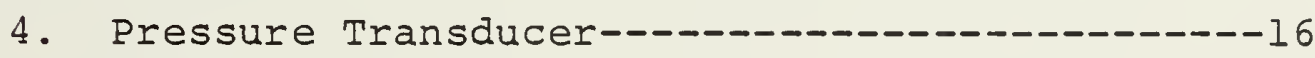

III. ANALYSIS OF DATA--_-_-_-_-17

IV. THEORY--

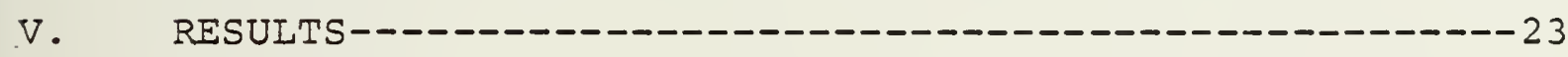

A. QUALITATIVE AND QUANTITATIVE DESCRIPTION OF THE

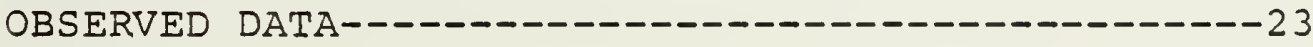

B. SURFACE ELEVATION SPECTRUM CALCULATED FROM PRESSURE SPECTRUM USING LINEAR TRANSFER FUNCTION

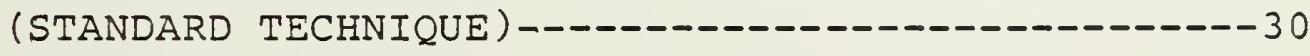

C. SURFACE ELEVATION SPECTRUM CALCULATED FROM PRESSURE SPECTRUM INCLUDING THE BERNOULII TERM---32

1. Bernoulli Term Calculated Using Measured

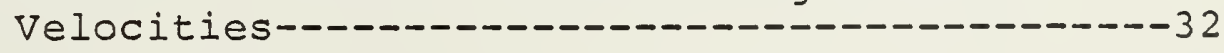

2. Bernoulli Term Calculated by Convolving

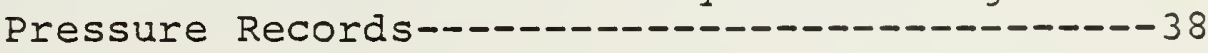

3. Comparing Variances----

VI. CONCLUSIONS-D-- 

APPENDIX A - BEACH PROFIIES--

APPENDIX B - CAIIBRATION FACTORS---

APPENDIX C - POWER, COHERENCE AND PHASE SPECTRA----------- 49

APPENDIX D - TABLES OF SURFACE ELEVATION SPECTRA--------- 61

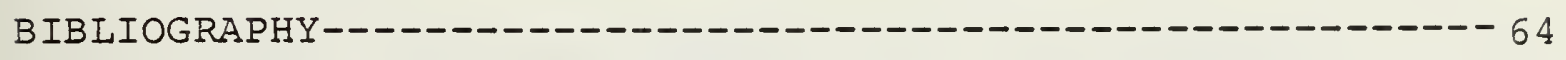

INITIAL DISTRIBUTION LIST----------------------- 65 



\section{LIST OF TABLES}

I. VARIANCE, STANDARD DEVIATION, SKEWNESS AND

KURTOSIS FOR ALL DATA-------

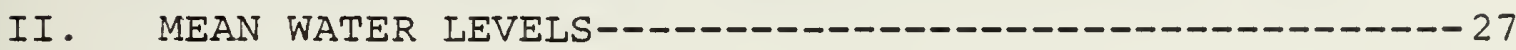

III. SURFACE ELEVATION SPECTRA FOR 19 JULY EVENING------33

IV. SURFACE ELEVATION SPECTRA FOR 8 MARCH------------- 37

V. COMPARISON SURFACE ELEVATION VARIANCES-------------42 

1. Pressure and Staff Elevations (Van Dorn, 1977)-----------11

2. Wave surface elevations measured by the wave staff

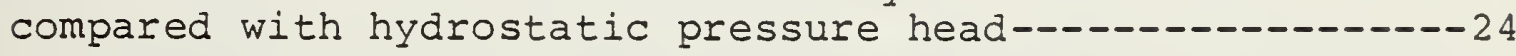

3. Mean water depth given by the wave gage and by the

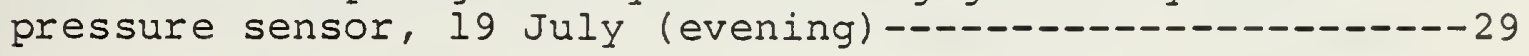

4. Power, Coherence and Phase Spectra for 19 July evening-

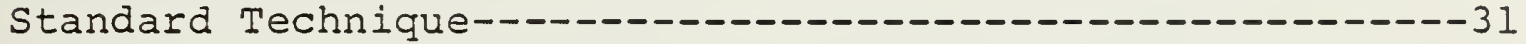

5. Power, Coherence and Phase Spectra for 19 July evening-

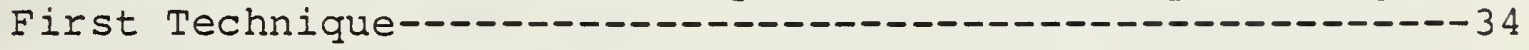

6. Measured and Computed Velocity Vectors, 19 July evening--36

7. Comparison of Measured and Calculated $u^{2}+v^{2}$ Spectra----39

8. Power, Coherence and Phase Spectra for 19 July evening---40 



\section{INTRODUCTION}

A. HISTORICAL PERSPECTIVE

In studying shallow water and breaking waves, many theoretical and practical problems are encountered. Analytical wave theories do not correctly characterize the physics of wave breaking. The environment is neither friendly nor easily reproduceable in a laboratory. A primary problem that is encountered is how to measure the wave height at or near the breaking point. In general, the two basic types of sensors used to measure the surface elevations have been subsurface pressure sensors and surface piercing wave gages.

The use of pressure sensors to infer surface elevation is particularly desirable as a means of conveniently measuring breaking waves, especially high energy waves. Pressure sensors have been used more commonly because, compared with surface piercing gages, they are rugged, less vulnerable to environmental hazard, and easier to install; in many locations, pressure sensors are the only feasible means of measuring the waves.

The conventional procedure used to infer surface elevation from a pressure signal is to calculate the energy density spectrum of a pressure record and to apply a spectral transfer function derived from linear theory. The pressure pulse is attenuated with depth, with the attenuation increasing with wave frequency. Hence, the spectral transfer function is dependent on frequency and depth. 

Esteva and Harris (1970) compared results from a wave staff and a pressure transducer in 16 feet of water. The pressure spectrum was compensated using Iinear wave theory to obtain the transfer function. The computed surface energy density spectrum was then summed over all components and the compensated root mean square of the total energy determined; this procedure led to good estimates of wave heights from pressure records as compared with those determined from surface records. However, a number of investigators have found discrepancies using the linear transfer function in intermediate to shallow water. Takahashi et al. (1967), Glukhovski (1961), Shooter and Ellis (1967), Gerhardt et al. (1955), suggest several different multiplicative correction factors to the linear transfer function for various conditions. In general the correction factors decrease with decreasing period, being greater than 1.0 for longperiod waves and less than 1.0 for short-period waves (Shore Protection Manual, U. S. Army, Corps of Engineers, 1975).

Near or at breaking, linear wave theory no longer is applicable, and using the linear transfer function does not give as good an approximation. Van Dorn (1977), in a laboratory study of breaking waves, found that surface elevations computed from pressure sensors were correctly measured in the troughs but were substantially less under the wave crests. At the crests, the surface elevations were sometimes 50 per cent too low as compared with wave staff measurements (Figure I). The discrepancy between pressure and wave staff measurements is caused by a dynamic pressure reduction due to the increased velocities 



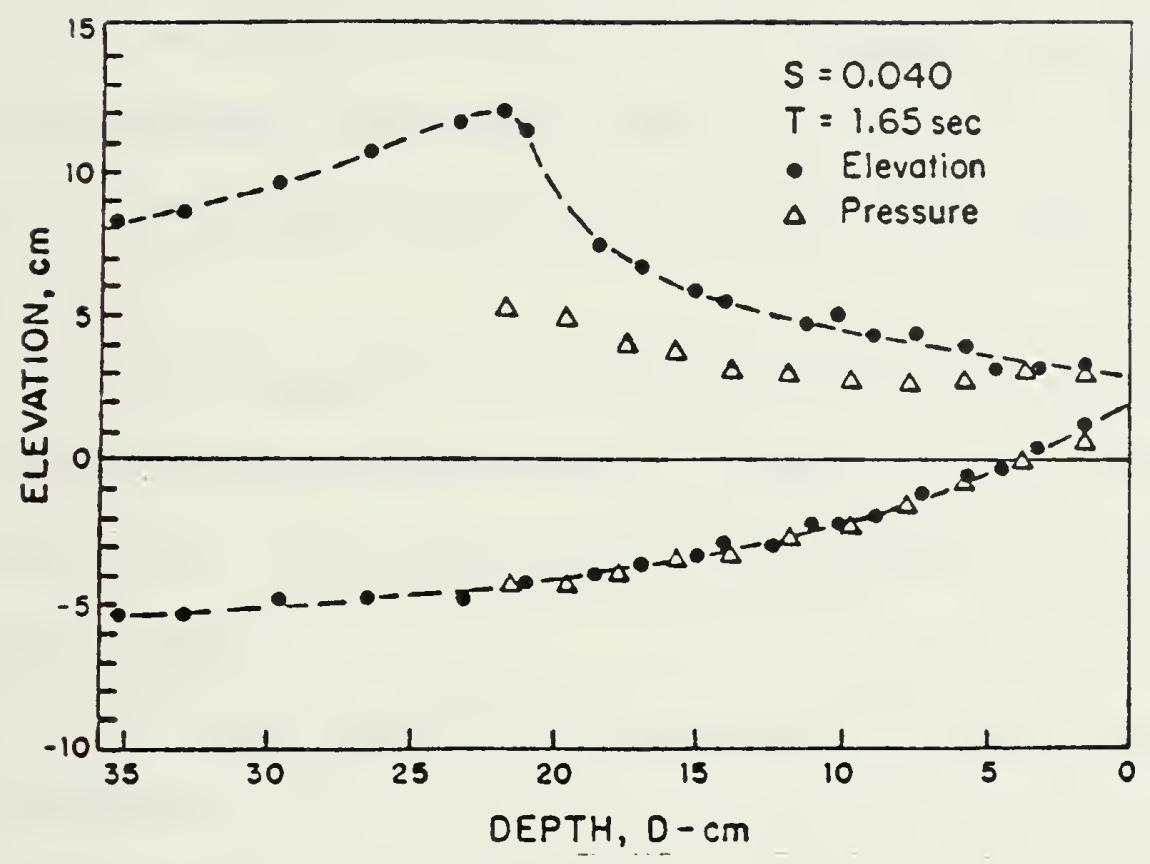

Figure 1. Hodographs of maximum and minimum waves elevations as an individual wave moves toward shore. Pressure and staff elevations agree under troughs, but peak pressure is clearly a poor indication of crest elevation. ( $S$ is beach slope)

From Van Dorn (1977) 

under the crests of breaking waves. Hence, the pressure records are much smoother and rounded off at the crests as compared with the surface staff measurements (Thornton et al., 1976).

\section{B. OBJECTIVE}

The objective of this research is to improve techniques for inferring surface elevations from the pressure sensors records and to test the techniques in the field under breaking waves.

Pressure is converted to surface elevation by including the non-linear velocity term which is usually neglected in the Bernoulli equation. Two techniques are proposed for including the Bernoulli term:

1. The Bernoulli term can be measured directly using flowmeters.

2. The Bernoulli term can be derived by convolving the pressure records to determine the velocities using shallow water linear theory. This technique has the advantage of requiring only pressure sensors.

Both techniques are equivalent to a second order perturbation scheme which includes the neglected non-linear term. 



\section{MEASUREMENTS}

\section{A. EXPERIMENT SITES}

For two locations within the surf zone sea surface elevations were observed using a wave staff and a pressure sensor while simultaneously the two horizontal orthogonal components, $u$ and $v$, of water particle velocity were measured. The data used in this paper were measured at Del Monte Beach and Scripps Beach, California.

Experiments were conducted at Del Monte Beach within Monterey Bay on 8 March 1978. The waves at this location were plunging-spilling breakers. Because of topographic sheltering and severe directional filtering due to refraction by the geometry of the bay, the waves offshore were narrow band swell type waves which impinged perpendicular to the shore; hence, a simplification to a two dimensional narrowbanded wave description is allowed. The median grain size is approximately $0.2 \mathrm{~mm}$ (taken at the water line) and the beach slope varied between $1: 14$ and $1: 40$.

Experiments were conducted at Scripps Beach at La Jolla on 19-20 July 1978, during the morning and evening of each day. Scripps Beach has an approximately planar 1:80 slope. The median grain size was $0.1 \mathrm{~mm}$. Spilling breakers predominated.

A typical beach profile for each experiment is shown in Appendix A. 



\section{B. INSTRUMENTATION}

During the Del Monte Beach experiments, the instruments used were a capacitance wave gage, two Marsh-McBirney model 721 electromagnetic current meters and a statham model PA506 pressure transducer.

Measurements at Scripps Beach were made using a resistance wire wave gage, one Marsh-McBirney model 512 flowmeter and the same pressure sensor used at Del Monte Beach.

\section{Capacitance Wave Gage}

The capacitance wave gage was fashioned from 3/8-inch outside diameter stainless steel rod. The rod was tightly covered with l/l6-inch wall thickness polypropylene tubing. The gage operates on the principle that a change in the plate dimension of a capacitor changes its capacitance and consequently an output voltage. The insulated steel rod and seawater act as the plates, the insulation functioning as the dielectric. As the surface elevation fluctuates, the capacitance of the circuit changes, and the output voltage responds linearly. These output voltage fluctuations were sensed by a transistorized circuit powered from the beach. The circuit was designed by McGoldrick (1969). The electronics package was housed in a watertight brass case which was mounted on a tower during the 8 March experiment. This allowed the connecting leads to be less than $30 \mathrm{~cm}$ long, thereby minimizing wire-to-wire capacitance. The gage was statically calibrated 

in the laboratory prior to the experiment. Accuracy was estimated to $.005 \mathrm{~m}$. For all experiments, the calibration factors are shown in Appendix B.

\section{Resistance Wave Gage}

The resistance wave gage is a surface-piercing, dualwire, resistance sensor. The wave staff wires were mounted on a 1.5-inch outside diameter, 1/8-inch wall fiberglass fishing pole of $5-\mathrm{m}$ length, epoxied into an aluminum flange at the bottom. The two resistance wires are 22 gage nichrome, attached to a PVC collar at the top of the pole and to the flange at the bottom. The wires are 4 inches apart over their entire length. A twisted-pair cable running inside the fiberglass pole connects the upper ends of the wires and provides. the electrical connection between the instrument package and the sensor wires. The gage operates on the principle that the total resistance measured between the nichrome wires at the top is proportional to the length of the exposed (not immersed) wire. The wires are the unknown resistance in an AC circuit, whose output is linearly related to the length of the exposed wire.

The wave gage was designed and built by the shore Processes Laboratory at Scripps Institution of Oceanography at La Jolla, California; field and laboratory tests have shown it to be durable both inside and outside of the surf zone, easily installed and operated, and highly linear. The instrument has a resolution of a few millimeters, accuracy better than one centimeter, negligible long-term drift and excellent temperature stability and frequence response. 



\section{Flowmeters}

The flowmeters used were Marsh-McBirney Models 721 and 512 Electromagnetic current meters. The flowmeter operation is based on Faraday's principle of electromagnetic induction. Each probe measures water particle velocity in two orthogonal directions through a range of zero to three meters per second, with a maximum output error of two percent. The flowmeters were dynamically calibrated with an oscillating platform attached to an eccentric arm drive by a variable speed motor. Measurement accuracy was determined to be $\pm .02 \mathrm{~m} / \mathrm{sec}$ during calibration.

\section{Pressure Transducer}

The pressure sensor used was a Gould Statham Model PA506 thin film strain gage. The sensing element is a vacuumdeposited resistive balanced fully active strain gage bridge with an output voltage responding linearly to the water depth. The sensor measures absolute pressure rather than relative, therefore variations in atmospheric pressure occuring during the experiments and or during calibrations will slightly influence the apparent mean water depth measured. The instrument has a resolution of few millimeters and a pressure range from 3 to 20 psi. The pressure sensor was statically calibrated in the laboratory prior to the experiments and measurement accuracy was determined to be $\pm .005 \mathrm{~m}$. 



\section{ANALYSIS OF DATA}

Continuous time series records of all measurements were collected within an hour or two on both the ebb and flow sides of high tide. Analogue records were made on both magnetic tape and strip charts.

The data were digitized at .2-sec intervals resulting in a Nyquist frequency of $2.5 \mathrm{~Hz}$ for the March experiment and at $.25-$ sec intervals resulting in a Nyquist frequency of $2.0 \mathrm{~Hz}$ for the July data. This sampling rate was sufficiently high to avoid aliasing of energy into the portion of the spectra which was of interest.

A mean value was computed for all data sets and the data were linearly detrended to remove tidal effects. Variance, standard deviation, skewness and kurtosis of the distributions were computed. Because the record lengths were slightly different for each run, there is a small difference in the frequency resolution for each run.

The power spectra of the wave gage and pressure sensor were calculated by using the Fast Fourier Transform (FFT) technique. A section of the record approximately 35 minutes long was used to calculate the power spectra. The 35 minutes were chopped into 20 blocks. Spectral estimates were obtained using the FFT were ensemble averaged over the 20 intervals resulting in approximately 40 degrees of freedom for each spectral estimate. 

A data window was applied to each interval to minimize leakage. The data window used was a cosine square taper function over the first and last $5 \%$ of the record.

Cross-spectra were computed between the wave and pressure records in the form of co- and quad-spectra. Coherence and phase spectra were then determined from the cross-spectra. Coherence and phase spectra as a function of frequency indicate the regions and degree of linear relationship and phase between the wave gage and pressure sensor data. 



\section{THEORY}

Assuming an irrotational, incompressible flow, a velocity potential $\phi$ exists and is described as:

$$
u=-\frac{\partial \phi}{\partial x} \quad \mathrm{v}=-\frac{\partial \phi}{\partial y} \quad \mathrm{w}=-\frac{\partial \phi}{\partial z}
$$

where $u, v$ and $w$ are the velocity components in the horizontal and vertical directions respectively. Since the mean hydrostatic pressure is constant, only the pressure fluctuations about the mean, $\Delta p$, are of concern. The pressure fluctuations are described by the Bernoulli theorem as:

$$
\Delta p(t)=\rho \frac{\partial \phi}{\partial t}-\frac{1}{2} \rho\left(u^{2}+v^{2}+w^{2}\right)
$$

where $p$ is density. The first term on the right is the pressure due to the wave form expressed in terms of the velocity potential and the second term is the contribution to $\Delta p$ due to the kinetic energy of the water motion induced by the passage of the wave. The second term on the right will be referred to hereafter as the Bernoulli term.

In deep water, the non-linear Bernoulli term can generally be neglected and the solution for linear theory is:

$$
\Delta p(\sigma, t)=\rho g \frac{\cosh k(d+z)}{\cosh k d} n(\sigma, t)=\frac{1}{H(\sigma)} \eta(\sigma, t)
$$



where $H(\sigma)$ is the linear spectral transfer function relating pressure to the surface $\eta(t)$, and $\sigma$ is the radial frequency. In the spectral domain

$$
S_{\eta}(\sigma)=|H(\sigma)|^{2} S_{\Delta p}(\sigma)
$$

In shallow water and in the vicinity of the breaker point, the contribution to $\Delta \mathrm{p}$ by the Bernoulli term becomes important. Confining the discussion to shallow water waves, $w$ is at least one order of magnitude less than $u$ and $v$ (making $w^{2}$ very small compared to $u^{2}$ and $v^{2}$ ), so that the contribution that $w$ makes to the Bernoulli term can be neglected. In shallow water, the ratio of the means of the two terms on the right hand side of (2) with pressure meter located on the bottom is (Kinsman, 1965):

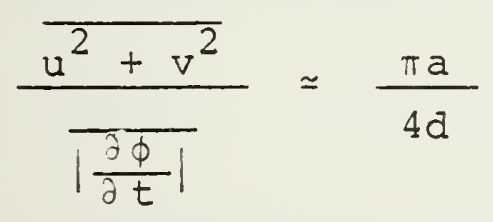

where $\mathrm{a}$ is the amplitude and $\mathrm{d}$ is the depth. Substituting the saturation relationship at breaking for solitary wave theory:

$$
\mathrm{a}=.39 \mathrm{~d}
$$

into (5) shows the ratio at breaking can become as large as $30 \%$. Two techniques for converting pressure to surface elevation are proposed which include the Bernoulli term. Starting with (2) and including the Bernoulli term, 



$$
\Delta p(\sigma, t)=\frac{1}{H(\sigma)} \eta(\sigma, t)-\frac{\rho}{2}\left(u^{2}+v^{2}\right)
$$

or

$$
\begin{aligned}
\eta(\sigma, t) & =H(\sigma)\left[\Delta p(\sigma, t)+\frac{\rho}{2}\left(u^{2}+v^{2}\right)\right] \\
& =H(\sigma) \mathrm{f}(\sigma, t)
\end{aligned}
$$

In the first technique proposed, $u$ and $v$ are measured in the field with electromagnetic flowmeters and the Bernoulli term computed and added to the differential pressure. The spectrum of the surface elevation is calculated from the combined time series

$$
S_{\eta}(\sigma) \quad=|H(\sigma)|^{2} S_{f}(\sigma)
$$

The second technique requires only a pressure measurement. The velocity used in the Bernoulli term is calculated by convolving the pressure record

$$
u(t) \quad=\int_{-\infty}^{+\infty} h(\tau) \Delta p(t-\tau)
$$

where the weighting function $h(\tau)$ is given by the Fourier transform of the transfer function

$$
h(\tau)=\int_{-\infty}^{+\infty} H(\sigma) e^{i 2 \pi f \tau} d \sigma
$$

The transfer function derived from linear theory can be used as a first approximation. For shallow water waves, the pressure is essentially hydrostatic and the waves are nondispersive. Hence, the transfer function is independent of frequency and the weighting function is independent of time. 

The velocity is easily calculated for this simplified case as:

$$
u(t) \quad=\frac{\sigma}{k \rho g} \Delta p=c \frac{\Delta p}{\rho g}
$$

where celerity, $c$, is given as a first approximation by:

$$
\text { c } \quad=\frac{\sigma}{\mathrm{k}}=\sqrt{\mathrm{gh}}
$$





\section{RESULTS}

A. QUALITATIVE AND QUANTITATIVE DESCRIPTION OF THE OBSERVED DATA

Due to the similarity of the spectral shapes of the various analysed data the discussion of results will be exemplified by the data of $19 \mathrm{July}$ evening. Except as were noted, the 19 July evening results are representative of the other data. Appendix $C$ contains the spectra calculated for all experiments.

Surface elevations measured using the wave staff are compared in Fig. 2 to the hydrostatic pressure head and the hydrostatic pressure head including the Bernoulli term.

The pressure sensor and wave staff records generally agree in areas near the wave through, but the pressure sensor underestimates the region near the crest as shown in Fig. 2. The results are in accord with the laboratory study of Van Dorn (1977). Referring to Eq. 2, the hydrostatic pressure fluctuations under crests and troughs is given by:

$$
\Delta p=\rho g \eta-\frac{1}{2} \rho\left(u^{2}+v^{2}\right)
$$

The second term on the right hand side of Eq. 14, i.e., the Bernoulli term, is always a reduction in pressure relative to hydrostatic; since $u$ and $v$ become maximum under crests and minimum at the troughs, the $\Delta p$ term is more reduced under the crests than at the troughs relative to hydrostatic. 

WAVE SURFACE EIJEVATIONS (METERS)

$-0.4$ $-02$ 0.2

in

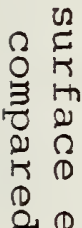

$\Sigma \stackrel{0}{0}$

ก

趉

을

今

is

(1)

ก

$\therefore 8$

它

थ

己

ए

ग

(1)
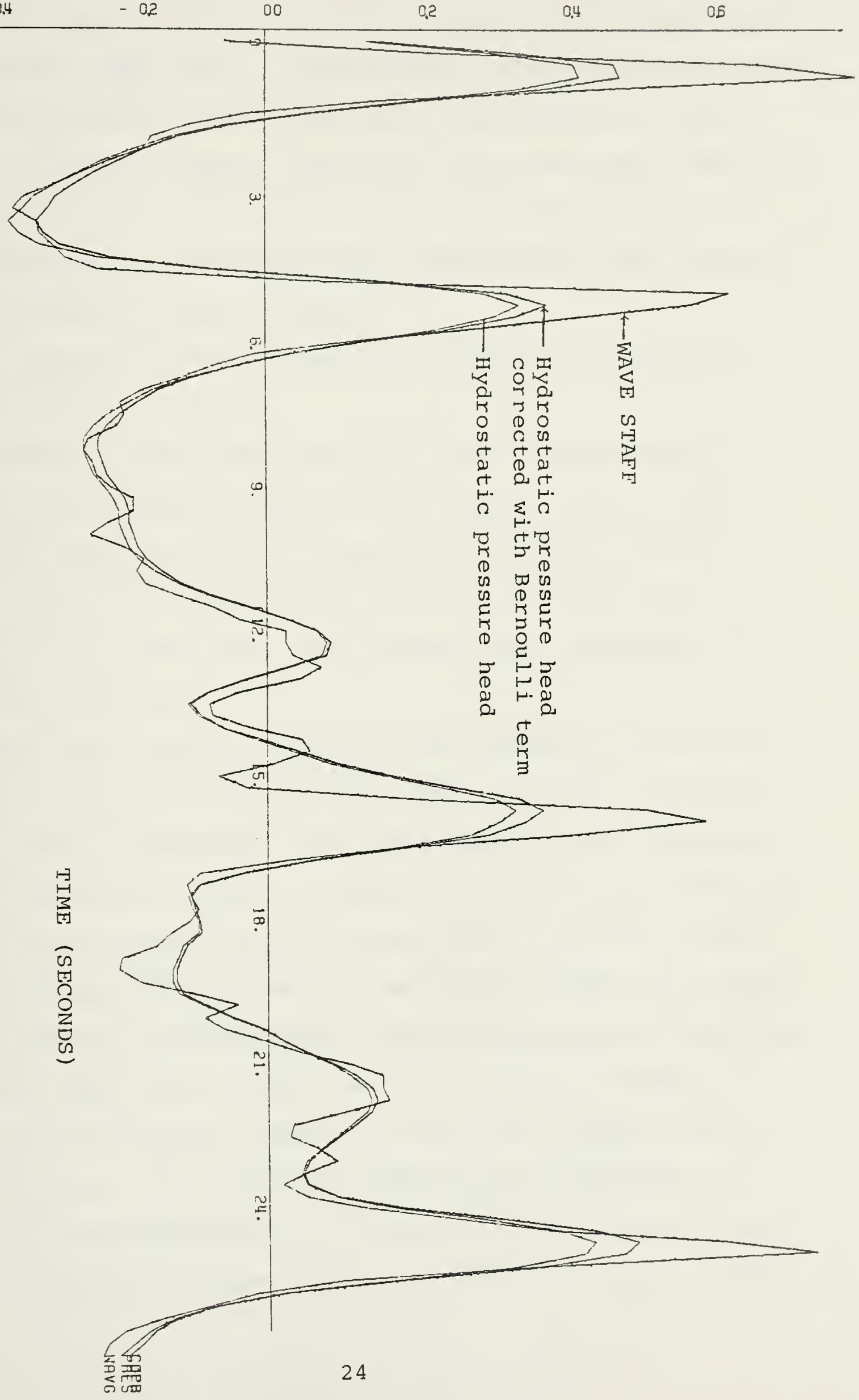

The sea surface given by the wave staff and the hydrostatic pressure head were found to have positive skewness and kurtosis, with larger values for the wave staff distribution. Larger values of positive skewness imply that the wave staff indicates larger heights for the crests. Larger kurtosis for the wave staff indicates, as expected, more peaked crests than observed by the hydrostatic pressure head.

The variance, standard deviation, skewness and kurtosis are summarized in Table I.

A measure of the total energy in the measured spectra is given by the variance. Variance was computed for all data sets. For the wave staff it ranged from .0335 to $.0471 \mathrm{~m}^{2}$, and for the pressure sensor from .0247 to $0.377 \mathrm{~m}^{2}$. The variances of the wave staff were always larger than for the pressure transducer.

A mean water surface elevation was computed for all data sets. The location of the breaker point is highly dependent on the depth of the water. The tidal range at both locations is approximately 1.5 meters, resulting in the breaker location changing considerably during a tidal cycle. During a tidal cycle it was possible to measure waves both inside and outside the surf zone. The mean depths during measurements, calculated using wave staff and pressure sensor are given in Table II along with the relative location of the mean breaker line and type of breaker. The mean sea surface values measured with the wave staff ranged from 1.57 to $2.03 \mathrm{~m}$, whereas the pressure sensor measurements ranged from 1.39 to $1.87 \mathrm{~m}$. For all data, 



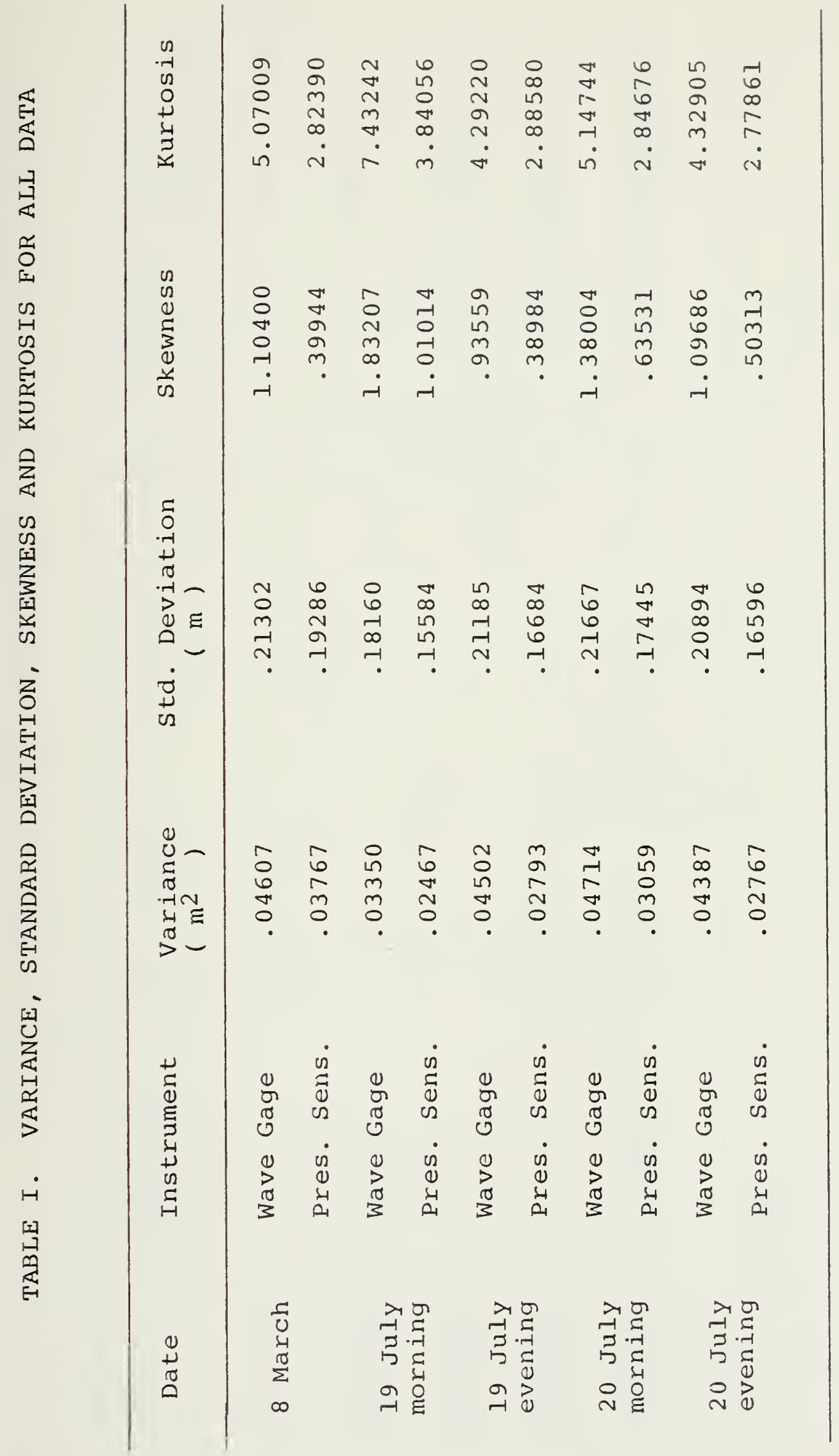





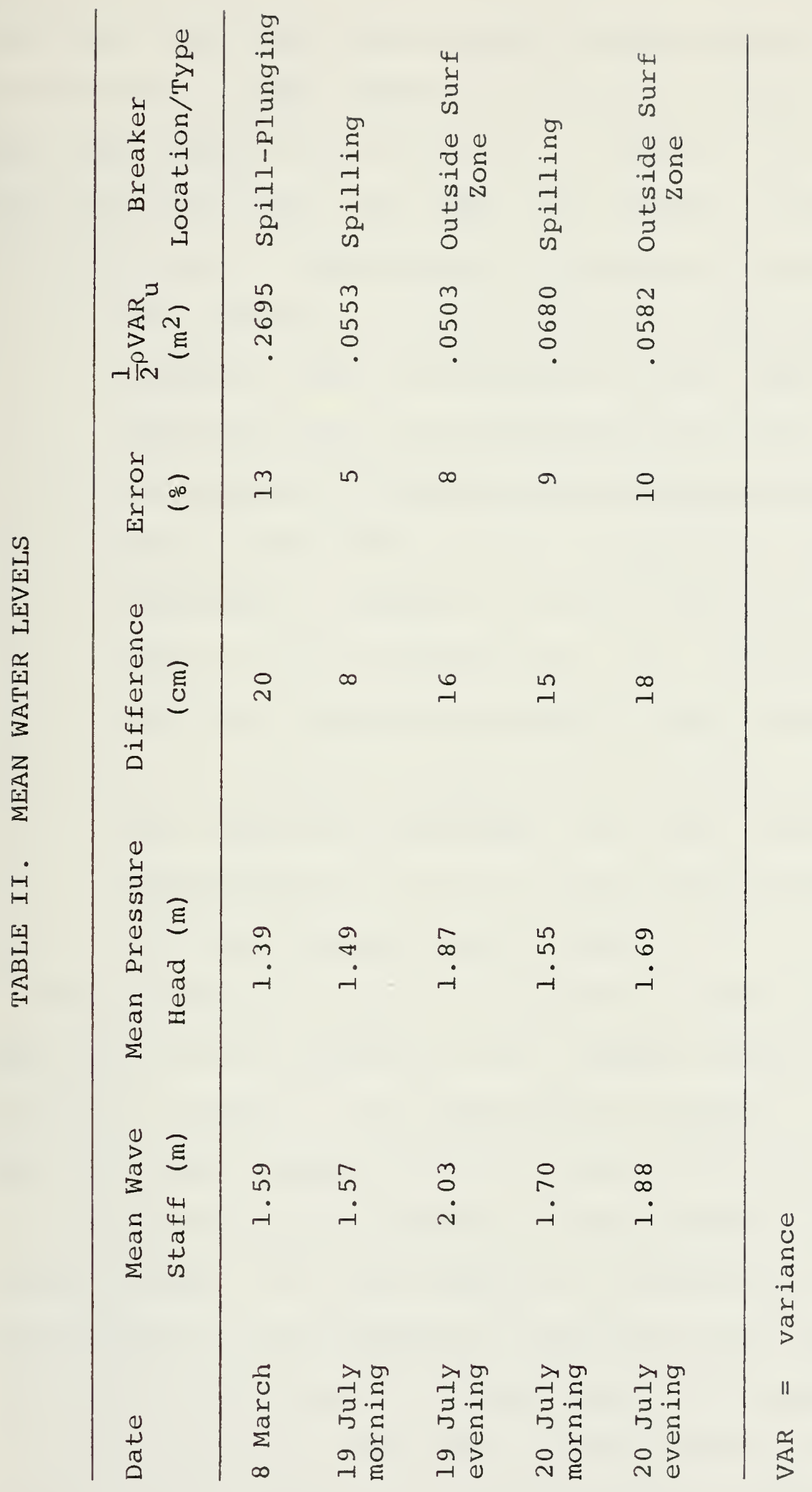



The mean water depth given by the pressure sensor is less than the mean water depth measured with the wave staff by a difference that ranged from .08 to $.20 \mathrm{~m}$. (Figure 3 the mean water level measured using wave staff and pressure sensor.) This difference can be explained due to two main factors:

1. The hydrostatic pressure head is decreased by the Bernoulli term and therefore gives a mean value less than the mean value measured by the wave staff.

2. The pressure transducer used measures absolute pressure rather than relative; therefore, variations in atmospheric pressure occurring during the experiments and or during calibrations, will influence the water surface elevations measured by the pressure sensor. As an example, a variation of .5 inch of mercury in the atmospheric pressure, will give a difference of approximately $17 \mathrm{~cm}$ in the mean water depth computed with the pressure sensor data.

The difference between the mean water level measured using the wave staff and pressure sensor ranged between 8 to $20 \mathrm{~cm}$, as given in Table II. The approximate decrease in pressure head due to the Bernouli term is given by the variance of the on-offshore horizontal velocity. The Bernoulli contribution varied between 5 to $27 \mathrm{~cm}$, which is a substantial contribution. The magnitude of the Bernoulli term varies with location relative to the breaker point and the type of the breaker. Hence, it is concluded that substantial errors can be introduced in the mean water elevation in very shallow water using pressure sensors due to the Bernoulli term. 

DEPTH IN METERS

$\stackrel{\sim}{\Xi}$

气ิ

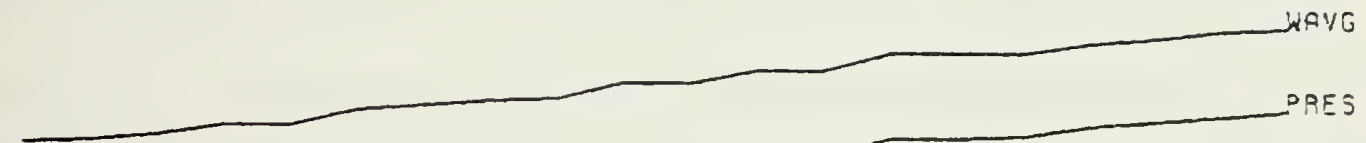

$\stackrel{4}{\Xi}$

$\stackrel{ }{\circ}$

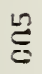

TIME (SECONDS)

$\Xi$

\section{Figure 3. Mean water depth given by the wave} gage and by the pressure sensor, 19 July

$$
\begin{aligned}
& \text { X-SCALE }=5.00 E+02 \text { UNITS INCH. } \\
& \text { Y-SCALE }=5.00 E-01 \text { UNITS INCH. }
\end{aligned}
$$



B. SURFACE ELEVATION SPECTRUM CALCULATED FROM PRESSURE

SPECTRUM USING LINEAR TRANSFER FUNCTION (STANDARD TECHNIQUE)

The pressure spectrum was converted to a theoretical wave spectrum for comparison with the measured wave staff spectrum using the transfer function given by linear theory. (Equation (3) in section IV.) The power, coherence squared (henceforth referred to as coherence), and phase spectra of the wave staff and pressure sensor are shown in Fig. 4 for the 19 July, evening. During the 19 July, evening measurements, the tide was high resulting in the wave sensors being located just out of the surf zone; hence, the waves are indicative of very shallow, non-breaking waves.

The power spectra shows a narrow-banded peak near a frequency of $.0938 \mathrm{~Hz}$ corresponding to a period of $10.7 \mathrm{sec}$. Also evident are peaks at approximately .1875 and .2734 Hz, which appear to be harmonics of the primary frequency at $.0938 \mathrm{~Hz}$.

In all the data, there is a relative peak of energy at a frequency of approximately $.02 \mathrm{~Hz}$, which we attribute to surf beat. Above approximately $.4 \mathrm{~Hz}$, the linear transfer function over-compensates and the surface elevation spectrum calculated from the pressure records diverges rapidly.

The coherence between surface elevation and pressure of all experiments were high, ranging from .95 to .99 in the maximum energy portion of the wave spectra. These extremely high coherences begin rapidy decreasing at approximately $.45 \mathrm{~Hz}$. The 8 March coherence spectrum is similar with the exception of the region below $.05 \mathrm{~Hz}$. In this region, the 8 March data 

POWER, COHERENCE AND PHASE SPECTRA 19 JULY EVENING
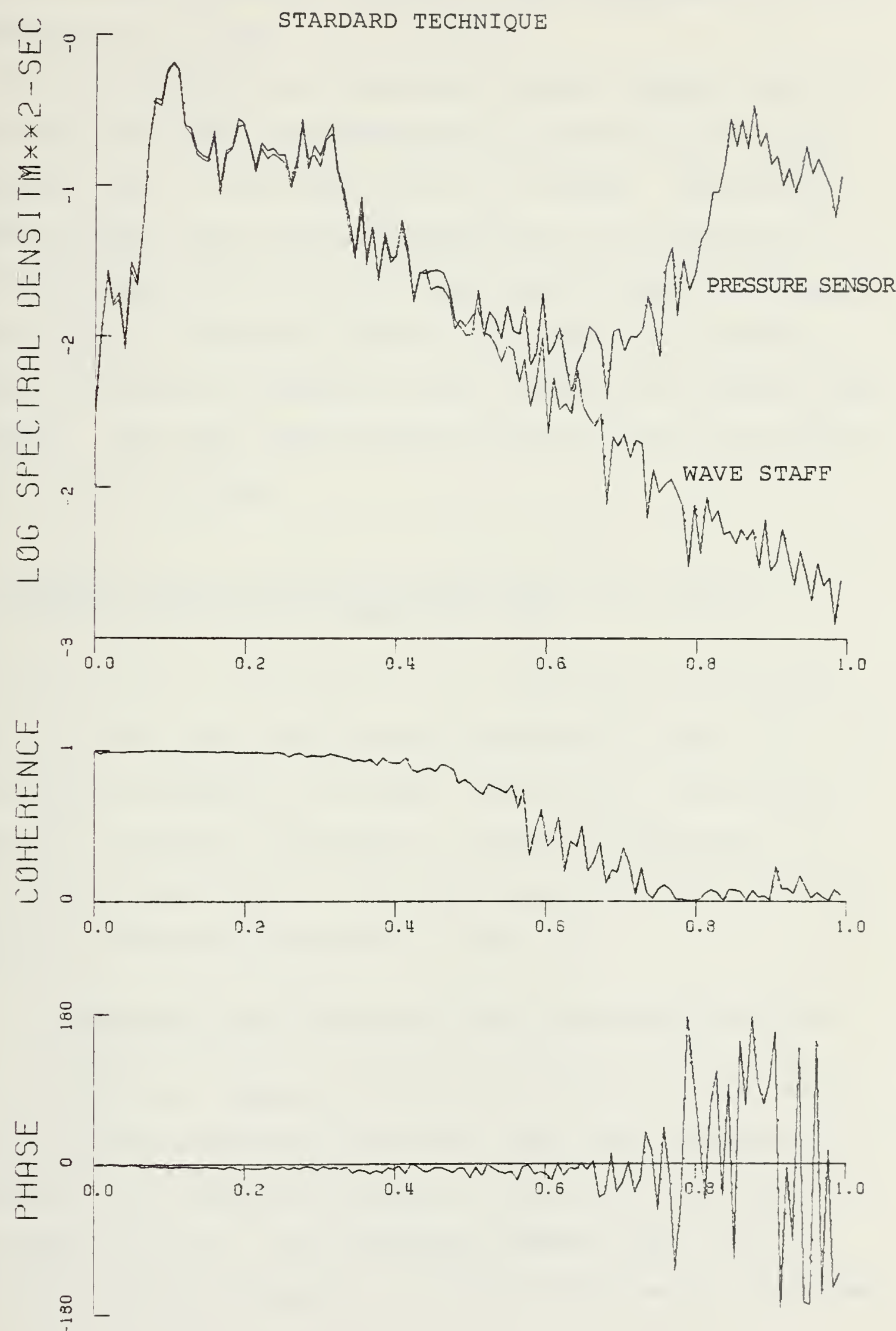

shows coherence values of .80 to .85 with a minimum of .68 at approximately . $.107 \mathrm{~Hz}$.

The phase difference between the pressure sensor and wave staff over the highly coherent band of prominent wave energy is always small in the range of 0 to 7 degrees. Because the pressure sensor was located approximately $40 \mathrm{~cm}$ shoreward of the wave staff, the wave staff phase always leads the pressure sensor phase. During the 8 March experiment, the pressure sensor was directly beneath the wave staff and the signals are in phase. The phase angle becomes random for the non-coherent region of the spectrum.

C. SURFACE ELEVATION SPECTRUM CALCULATED FROM PRESSURE SPECTRUM INCLUDING THE BERNOULLI TERM

As described in section III, two techniques are proposed here to include the usually neglected Bernoulli term, $u^{2}+v^{2}$, in converting pressure to surface elevations. The spectral densities of surface elevations at selected frequencies for the 19 July evening data, calculated using the three pressure correction techniques compared in Table III.

\section{Bernoulli Term Calculated Using Measured Velocities}

The first technique employs the Bernoulli term calculated using the measured velocities. The first technique is compared to the standard technique in Table III; the spectra are shown in Fig. 5. In frequencies ranging from .0156 to $.0313 \mathrm{~Hz}$ (surf beat region), the first technique has decreased 



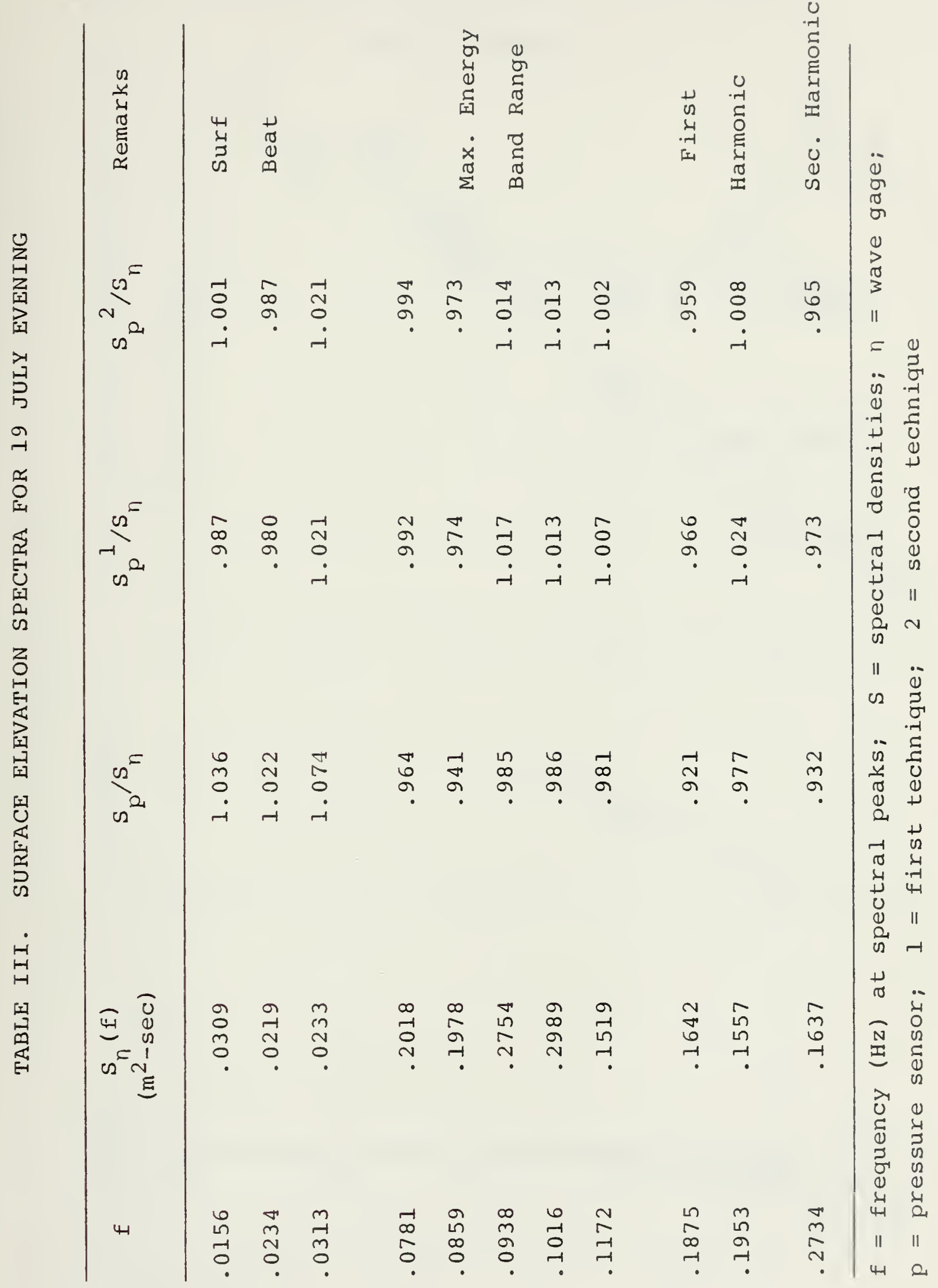



POWER, COHERENCE AND PHASE SPECTRA 19 JULY EVENING
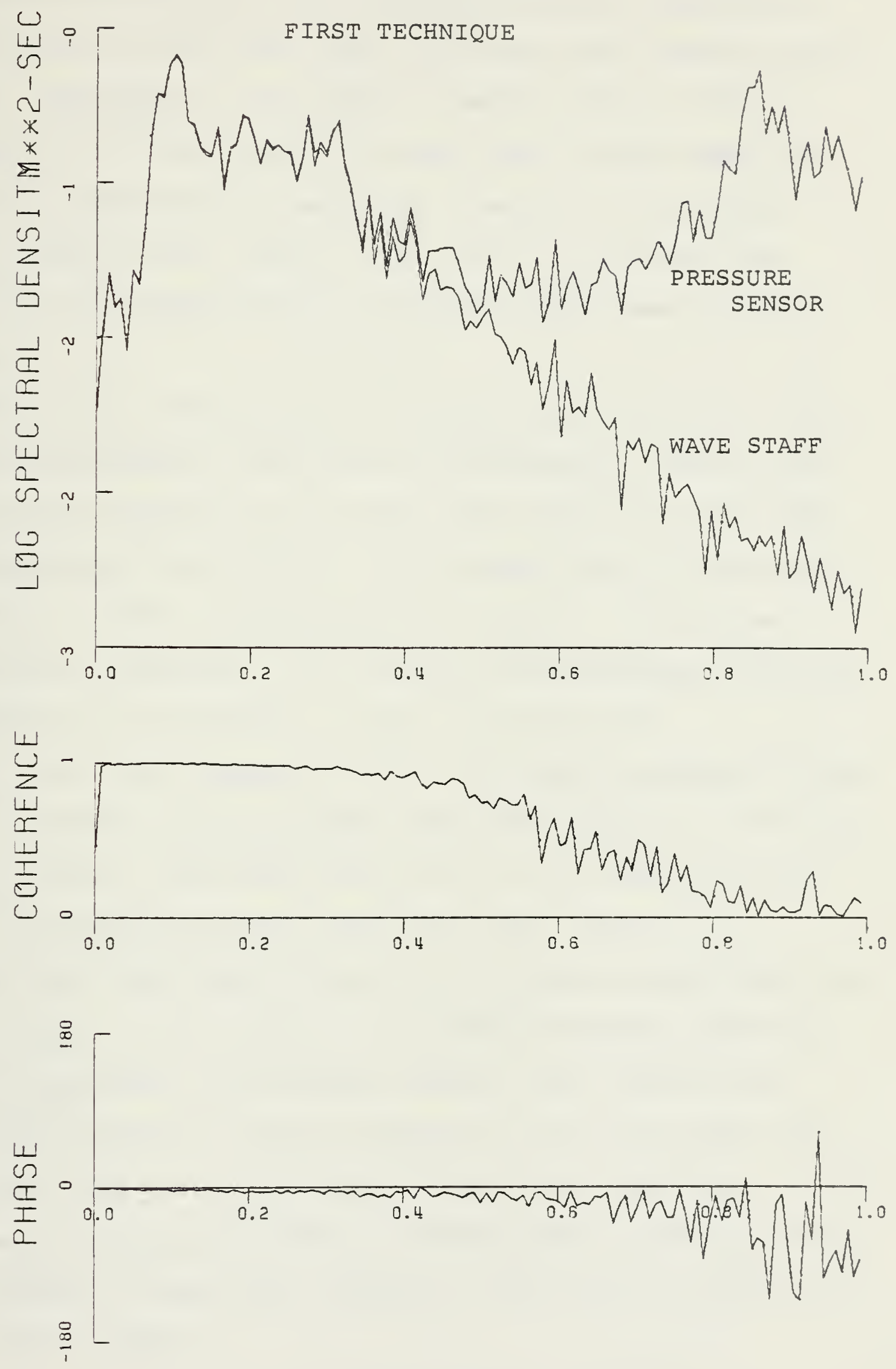

FREQUENCY $(H Z)$

Figure 5 

the spectral densities of the converted pressure spectrum to values closer to, but less than, the wave staff spectral densities. Referring to the spectral density ratios listed in columns 3-5 of Table III, it is noted that for the same frequencies, application of technique 1 improves the spectral density ratios from 1.036 to $.987,1.022$ to .980 and from 1.074 to 1.021 respectively; a relative improvement in all cases.

Without the introduction of the non-linear Bernoulli term, the pressure spectral densities are consistently smaller than the spectral densities of the wave gage spectrum in the band of frequencies from .0781 to $.1172 \mathrm{~Hz}$ where most of the energy is present. After the application of the $u^{2}+v^{2}$ term as evaluated by technique 1 , all values show improvement with the exception of the frequency .1016 $\mathrm{Hz}$ where the ratio of .985 was changed to 1.017 . The same is generally true for the harmonic spectral peaks, with the exception of the frequency .1953 Hz, where the ratio of .977 , the application of the first technique gives a ratio of 1.024 (see Fig. 6).

For the 8 March data (Table IV), in the frequency band that contains most of the energy, the standard pressure spectrum spectral densities are uniformly smaller than those of the wave staff spectrum, with the exception of the surf beat frequency of .0098 $\mathrm{Hz}$. Application of the first technique in the surf beat frequency of $.0098 \mathrm{~Hz}$ increased the spectral density ratio whereas in the first harmonic $(.1270 \mathrm{~Hz})$ we reduced the ratio .941 to .854 . 



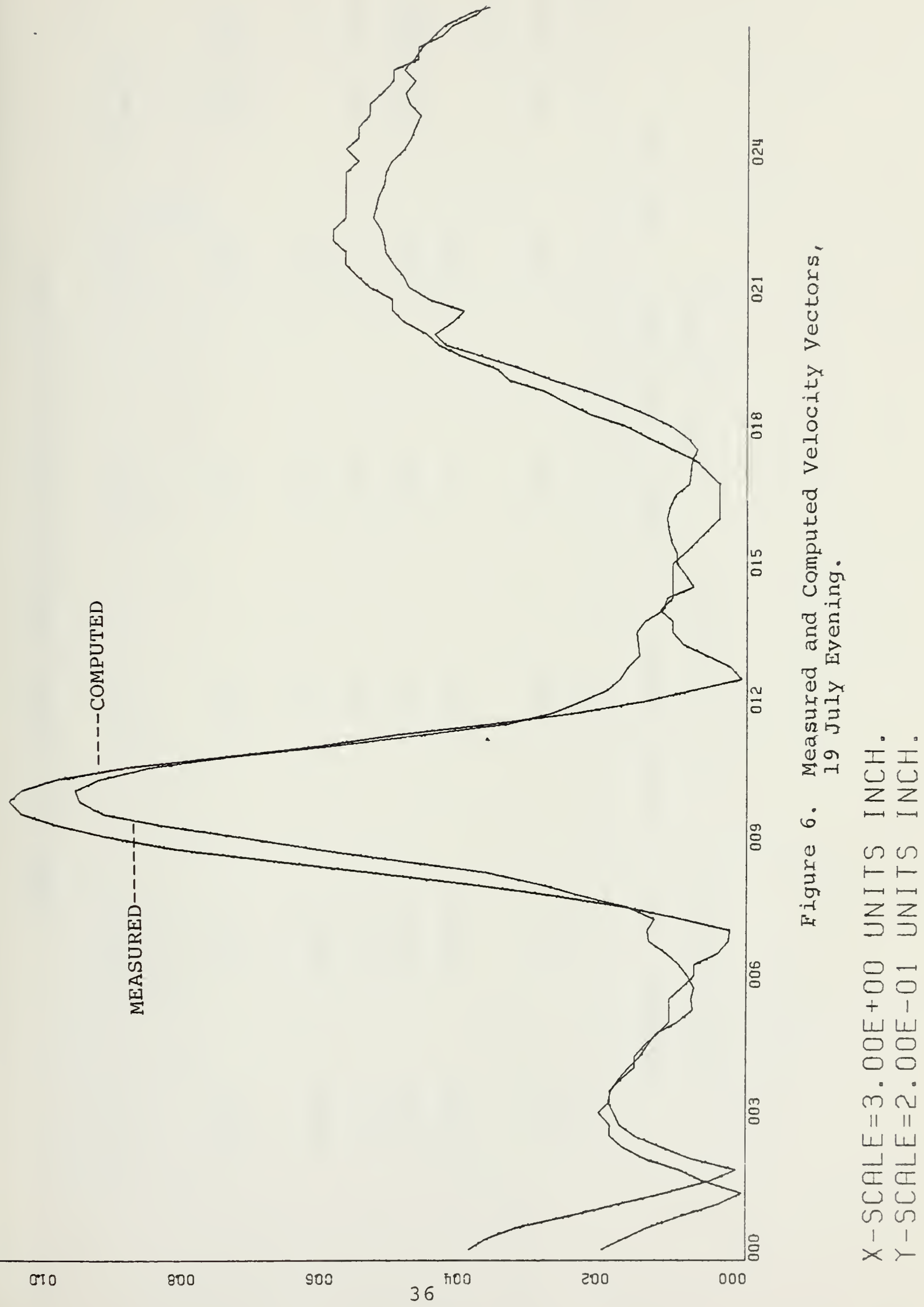





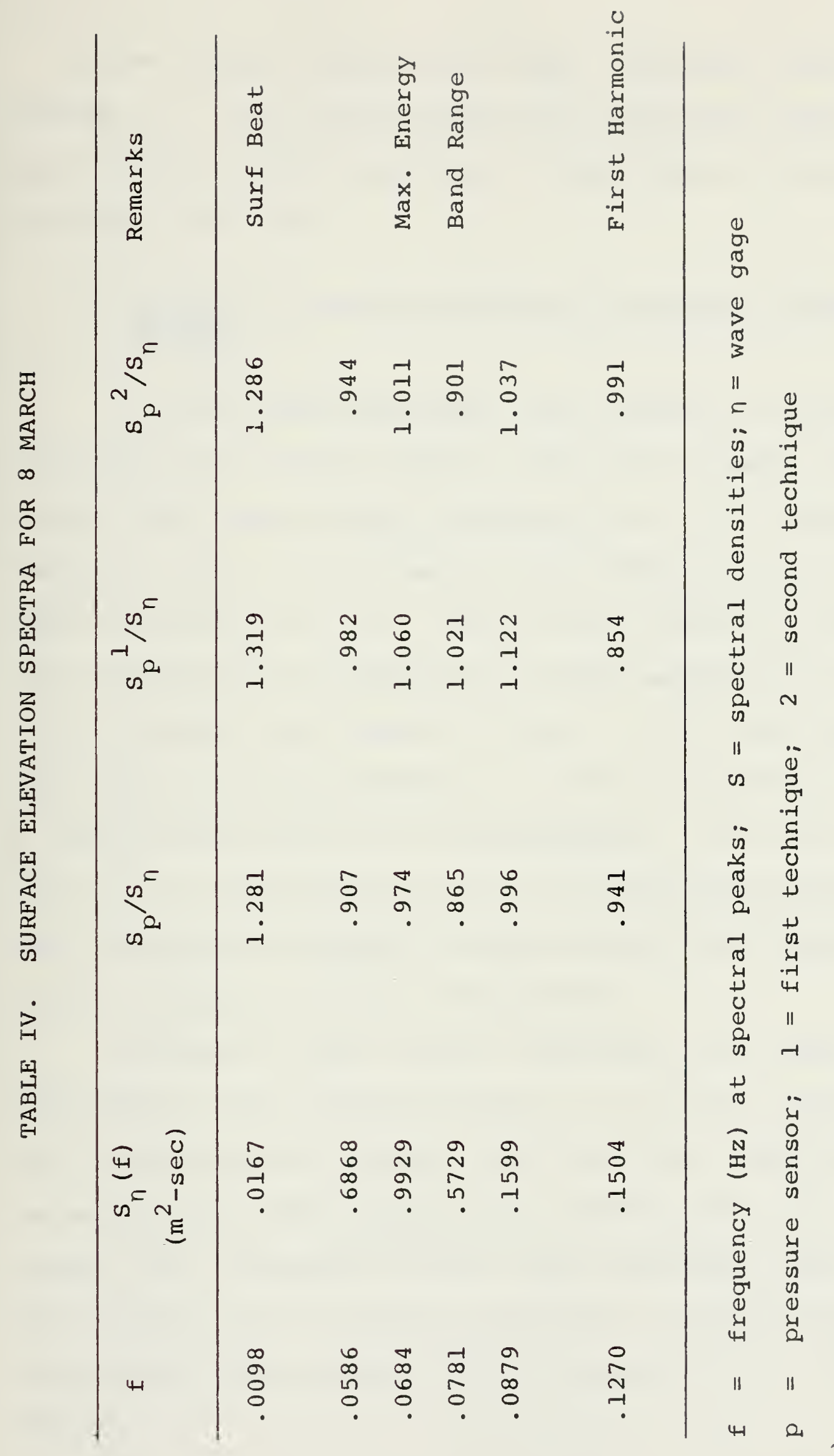



In the maximum energy band range, technique I gives better agreement for two of the frequencies $(.0586$ and $.0781 \mathrm{~Hz})$, but gives slightly poorer agreement in the other two frequencies $(.0684$ and $.0879 \mathrm{~Hz})$.

\section{Bernoulli Term Calculated by Convolving Pressure} Records

In the second technique, the velocity is calculated by convolving the pressure record, using the transfer function derived from linear theory as given by Eq. 12. A typical analogue record of both measured and computed vector magnitudes is shown in Fig. 6. The velocity vectors of the measured velocity and the computed velocity determined by convolution of pressure are compared in Fig. 7; the power spectra are very similar and high coherence and phase agreement in the band of frequencies smaller than approximately $.3 \mathrm{~Hz}$ are to be noted. Hence, it is concluded that the use of velocities calculated from the convolved pressure records should give reasonable results compared to direct measurements.

For the 19 July evening experiment, the improvement introduced by the second technique is, in fact, always better than the improvement obtained with the first technique, with the exception of the frequency of .0188 Hz, (Fig. 8). For the 8 March data, compared with the first technique, the improvement obtained with the second technique is better in all frequencies with the exception of the frequencies of .0586 and $.0781 \mathrm{~Hz}$. 


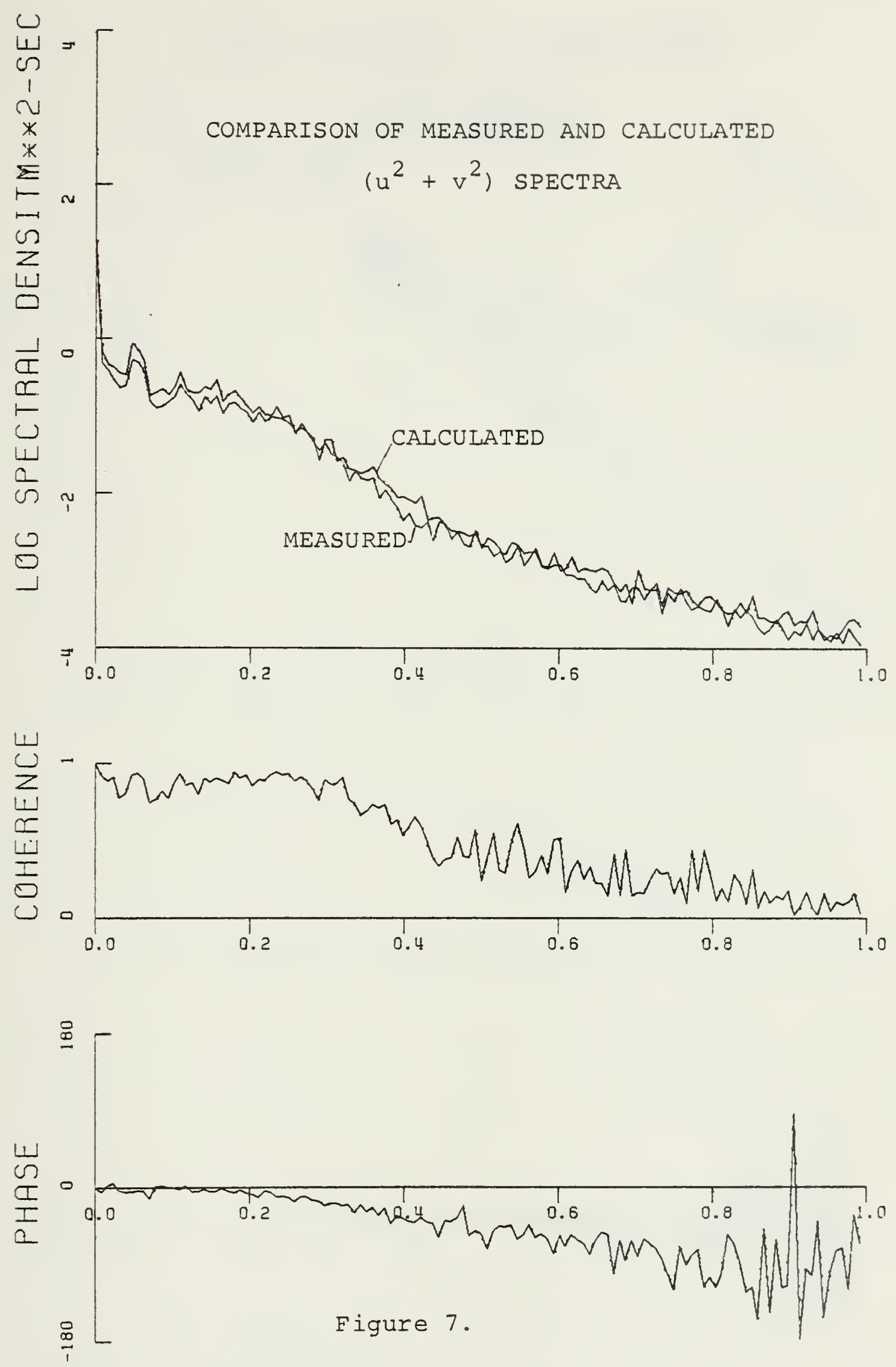

FREQUENCY (HZ) 


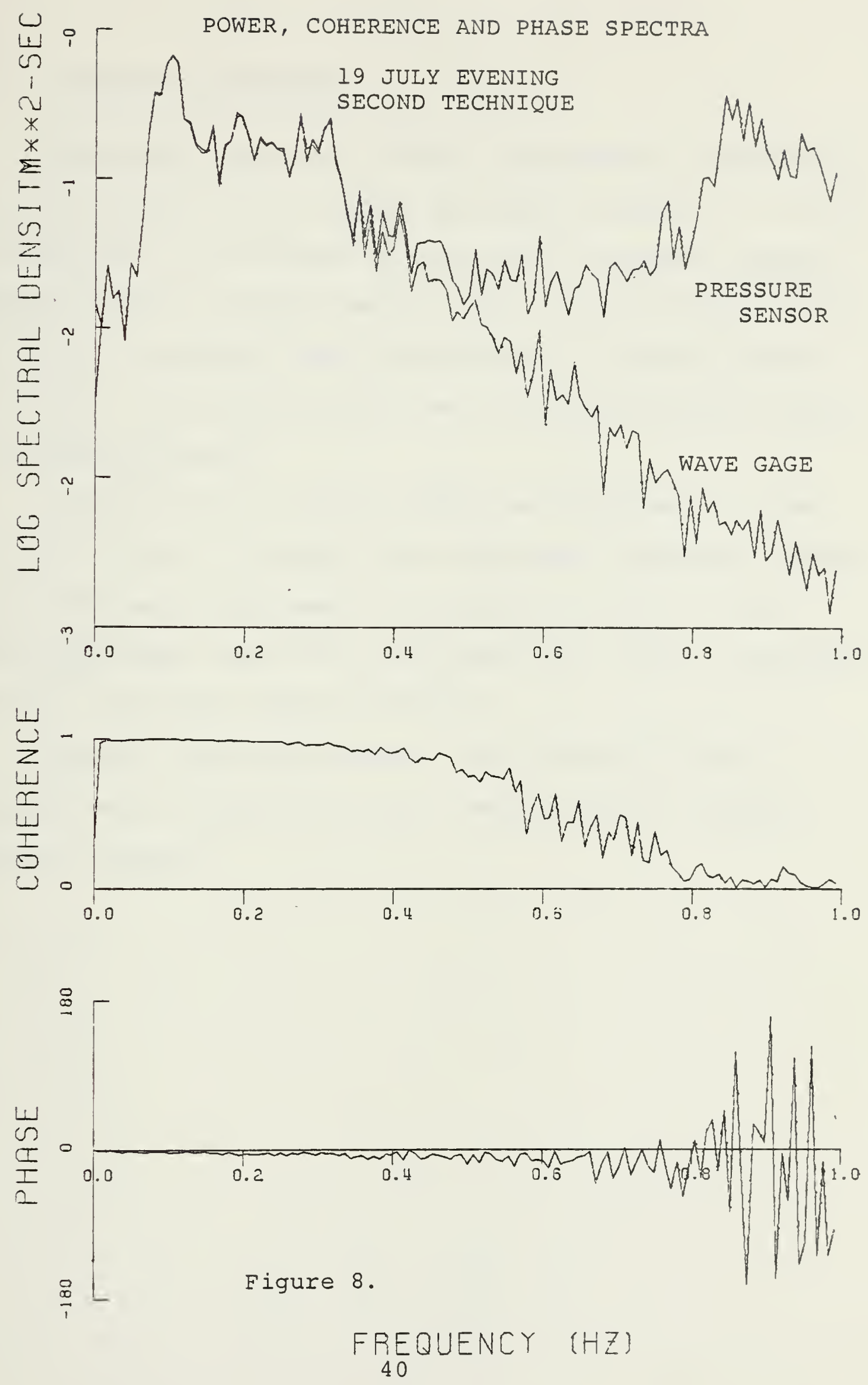



\section{Comparing Variances}

Variances (and their ratios) calculated by integrating the spectra from .007 to $.30 \mathrm{~Hz}$, are given in Table V. For all the experiments the variance of the surface elevation spectra computed from the pressure record using the conventional transfer functio 's smaller than the variance of the wave staff spectra, $w$. the exception for the $20 \mathrm{July}$ evening data where it is slightly larger.

For the 19 July evening data the improvement on the error was 3.4 and $3.1 \%$ using first and second technique respectively. The best improvement obtained was for the 19 July morning experiment where the improvement was $7.8 \%$ for technique 1 and $9.7 \%$ using the second technique.

For all other experiments, the inclusion of the Bernoulli term resulted in an over compensation of surface elevation variance. 



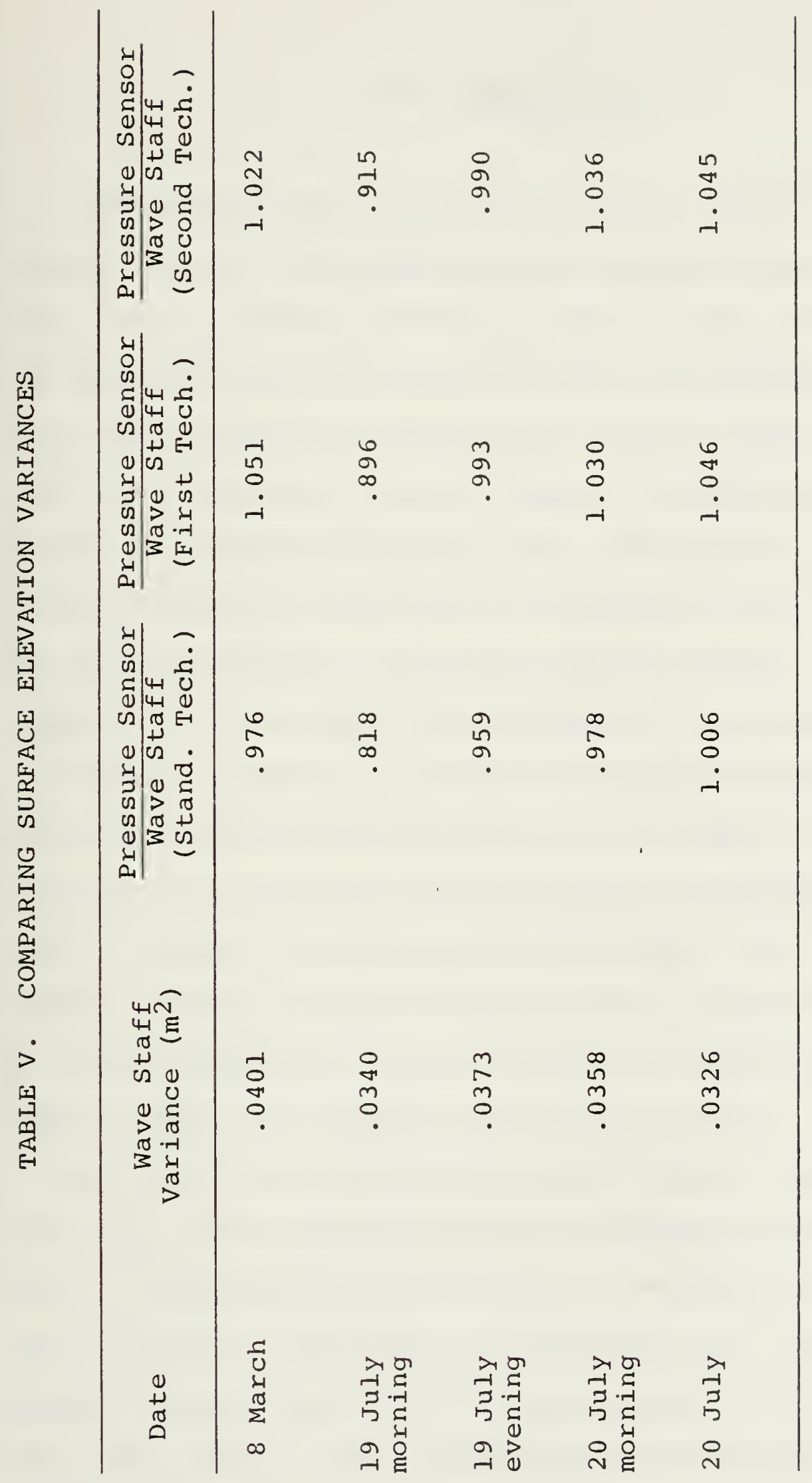





\section{CONCLUSIONS}

Field measurements of waves in very shallow water just outside the surf zone and at the breaking were measured with both a wave staff and pressure sensor. The surface elevation was inferred from the pressure using the conventional linear wave theory transfer function and a method which includes the non-linear quadratic velocity term in the Bernoulli equation. The velocities were measured using a flowmeter (technique 1) and calculated by convolving the pressure record (technique 2). The surface elevation inferred from the pressure sensor are compared with the wave staff records as a standard.

Surface elevations inferred from the pressure sensor were generally underestimated, mainly in the region of the crest, compared with the same surface elevation measured by the wave staff. Pressure records are more smoothed than wave staff records and for energetic computational purposes the energy of the wave measured with the pressure transducer is generally smaller than that measured with the wave staff.

The mean water levels determined from the hydrostatic pressure head were consistently less as compared with the wave staff. The difference can be due to variations of the barometric pressure (which was not accounted for) and due to the dynamic pressure head which acts to always underestimate the mean water level. Direct estimates show that the errors in the mean water level due to the dynamic pressure head ranged 

from 5 to 13 percent. Therefore, the use of pressure sensors to infer the mean water level must be interpreted with caution.

It is advisable to bury the pressure transducer in the sea bed to insure that it is out of the flow field and the dynamic pressure is essentially zero.

In the band of frequencies less than approximately $.4 \mathrm{~Hz}$ the pressure sensor and wave gage spectra are highly coherent and almost perfectly in -phase, whereas at higher frequencies the spectra become less coherent and the phases random, as noted previously.

Both proposed techniques for calculating the surface elevation spectrum from the pressure records show a general improvement as compared with the standard technique using a linear transfer function. For technique 1, improvement (on the order of 3.4 to $7.8 \%$ of the total variance of the wave gage spectrum) was obtained. Whereas, for the second technique the improvement was on the order of 3.1 to $9.7 \%$. The improvement of both techniques is approximately the same with the disadvantage of the first technique that the velocities are measured with flowmeters. In technique 2 the velocities are determined by convolving the pressure records which is a great simplification in an area where the emplacement of sensors is difficult, such as the surf zone.

For both techniques, the reason why the improvement is not so large can be explained by three factors:

1. The irrotationality assumption applied during the development of the Bernoulli equation leads to 

problems when the equation is applied to a rotational flow. Breaking waves are characterized by both rotational and highly non-linear flow.

2. In cases where foam-bearing waves are being measured, wave heights measured by the wave staff are always in excess of those indicated by the pressure transducer. The wave gage measures the wave amplitude as being to the top of the superimposed foam, whereas the added pressure at the pressure transducer due to the foam is relatively small.

3. The Bernoulli term is only a second-order correction. 

APPENDIX A

BEACH PROFILE AT DEL MONTE BEACH

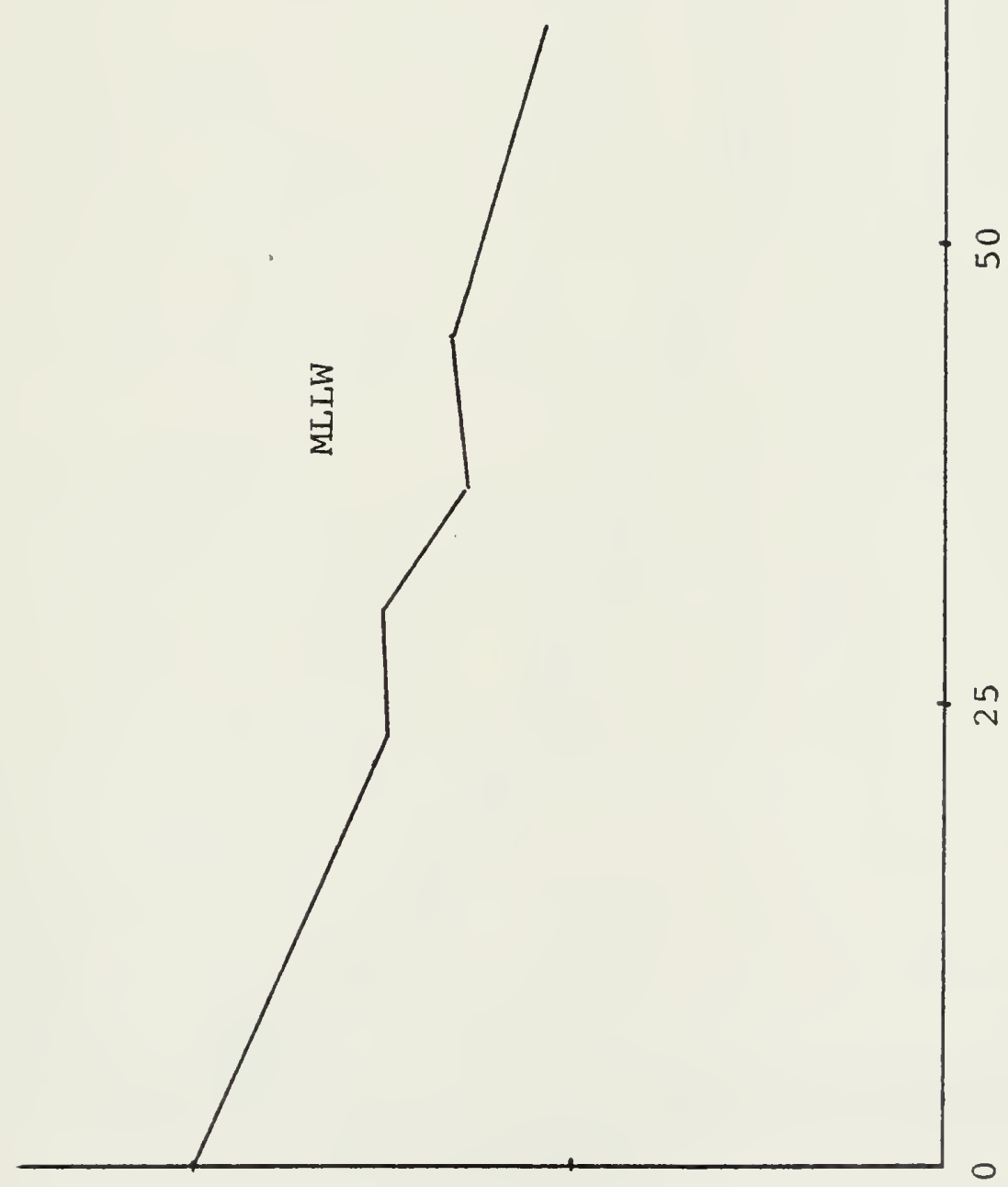

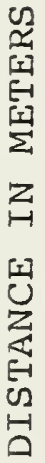

N $\Sigma$ 回世回嵒的

되十 되 $>\ll$ \& $H O Z$ 

BEACH PROFILE AT SCRIPPS BEACH

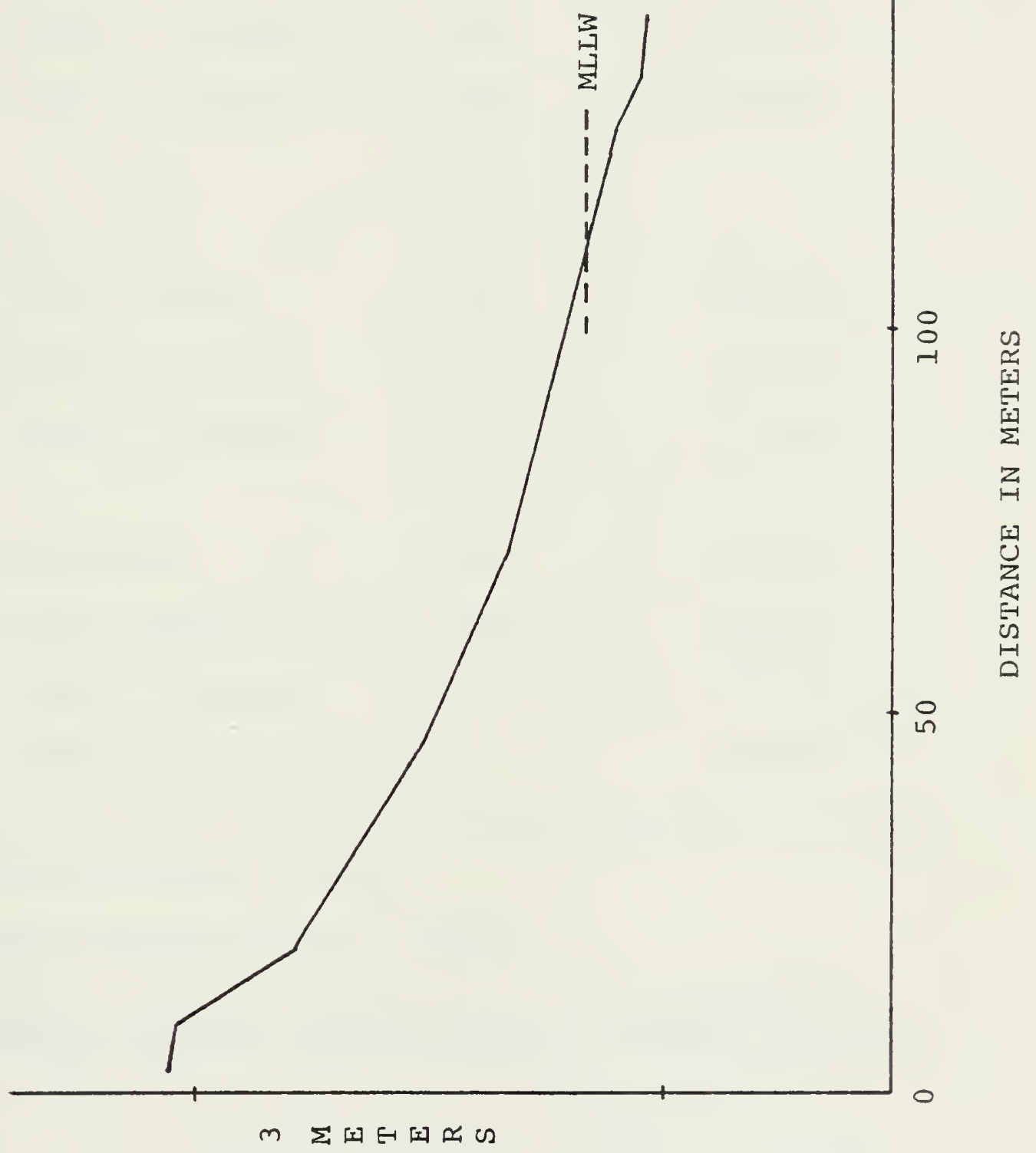

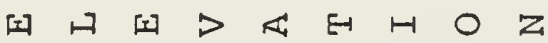





Date Instrument $\quad \begin{gathered}\text { Cala* } \\ \text { (meters) }\end{gathered} \begin{gathered}\text { Calx** } \\ \text { (meters/volt) }\end{gathered}$

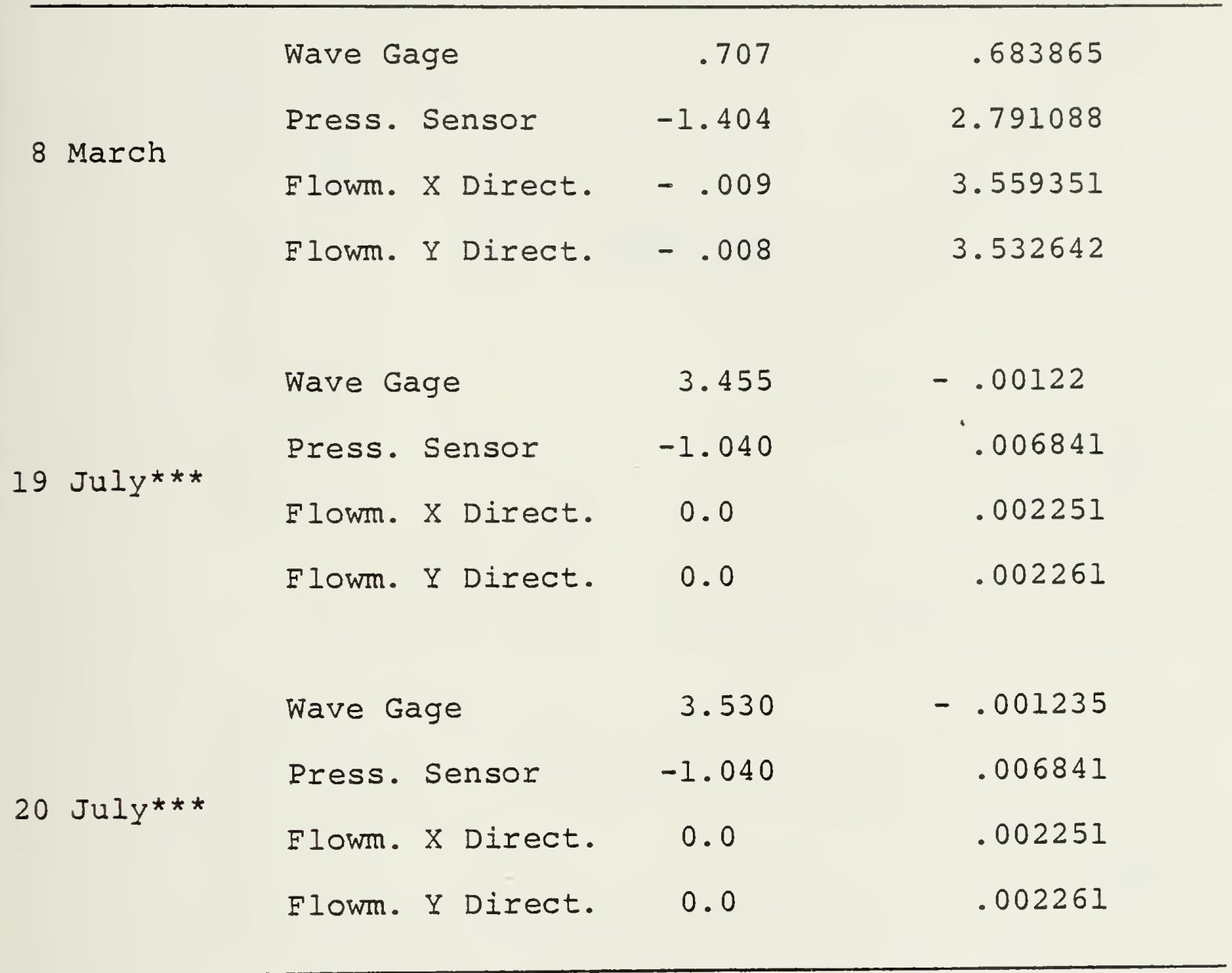

* Calibration Additive Factor

** Calibration Multiplicative Factor

*** Due computer record technique the true Calx of the instruments have been multiplied by a factor of 5/2048. 

APPENDIX C

POWER, COHERENCE AND PHASE SPECTRA FOR $8 \mathrm{MARCH}$
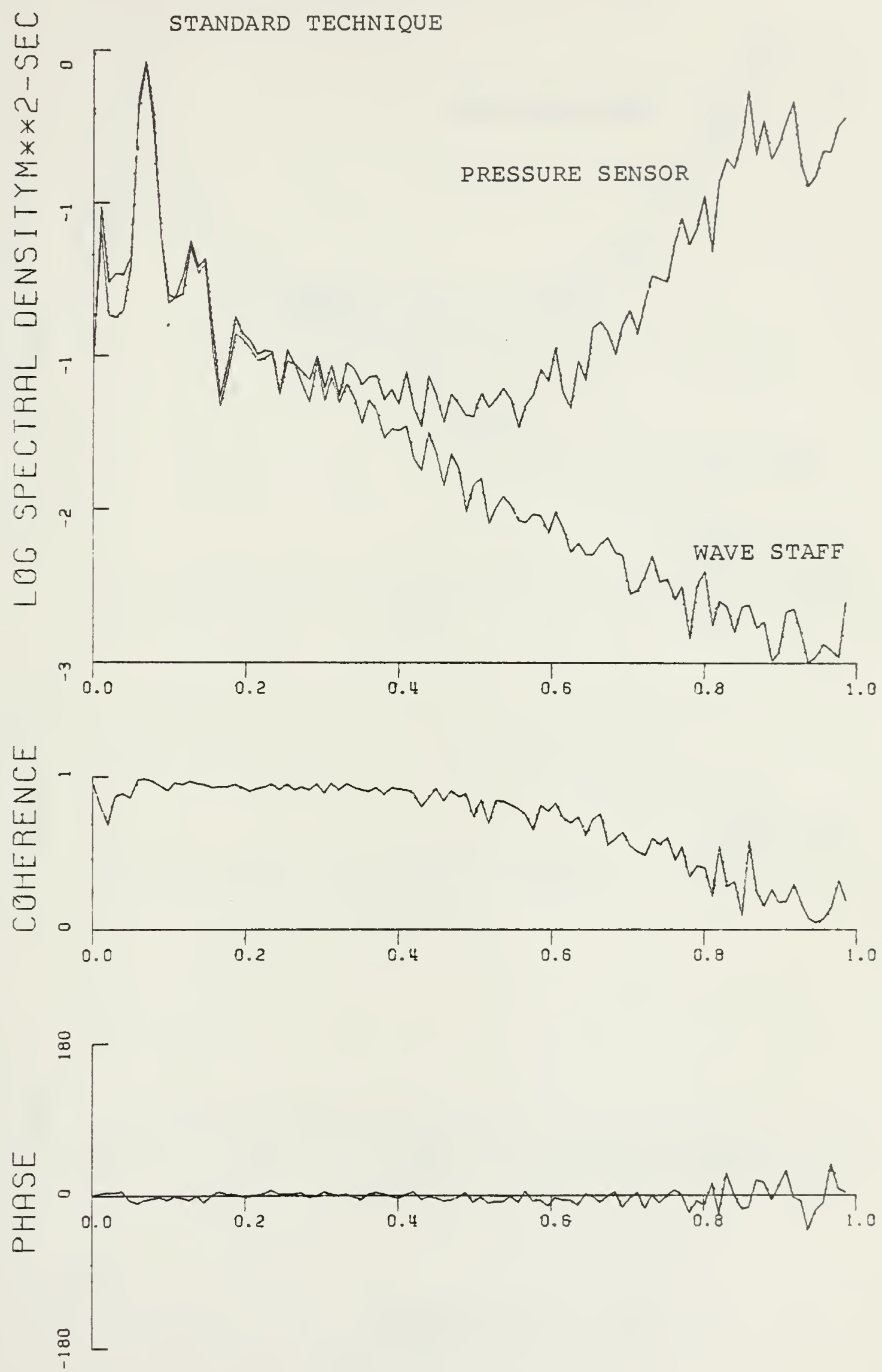

FREQUENCY (HZ) 

POWER, COHERENCE AND PHASE SPECTRA FOR 8 MARCH
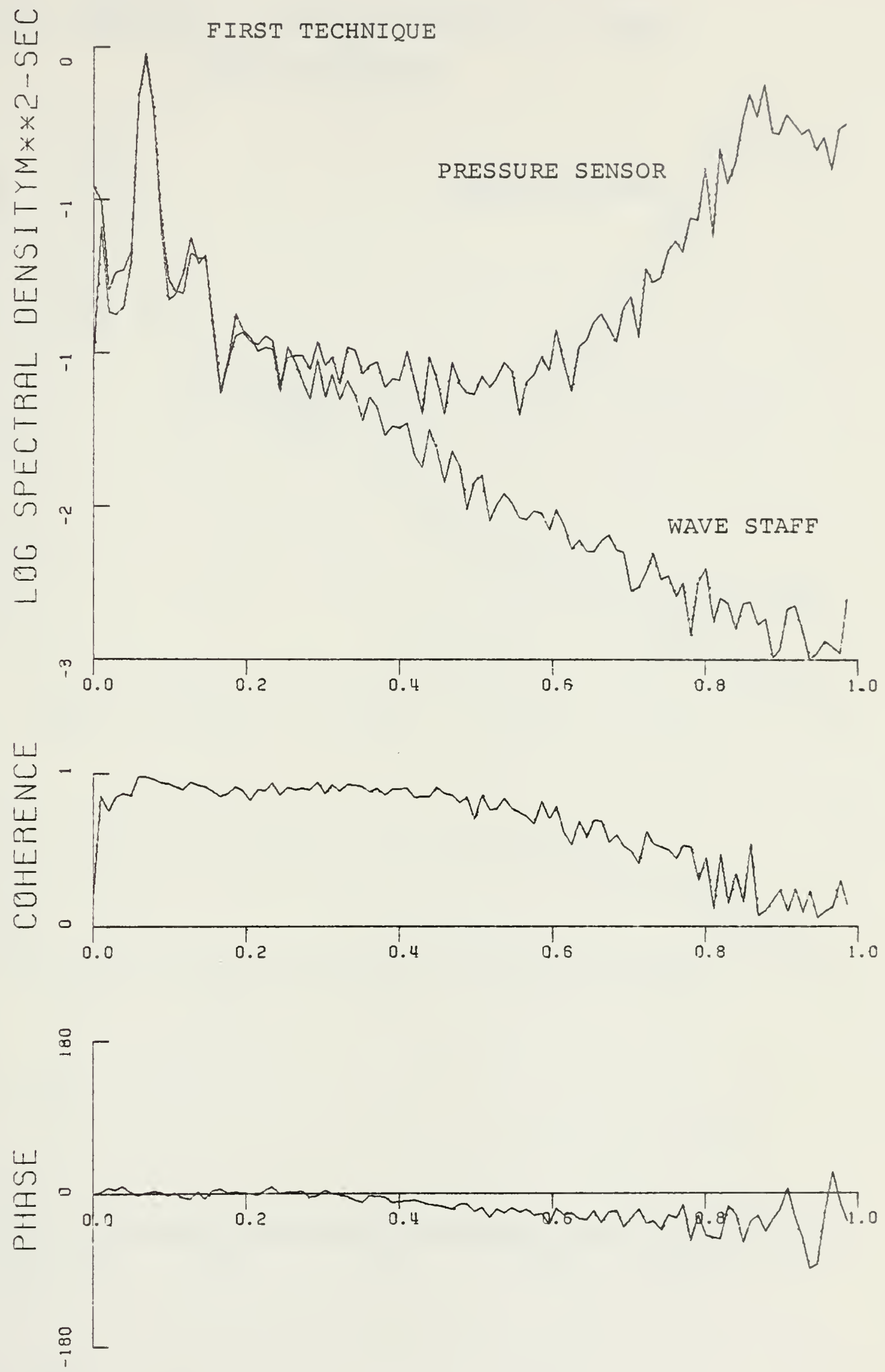

FREQUENCY (HZ) 

POWER, COHERENCE AND PHASE SPECTRA FOR $8 \mathrm{MARCH}$
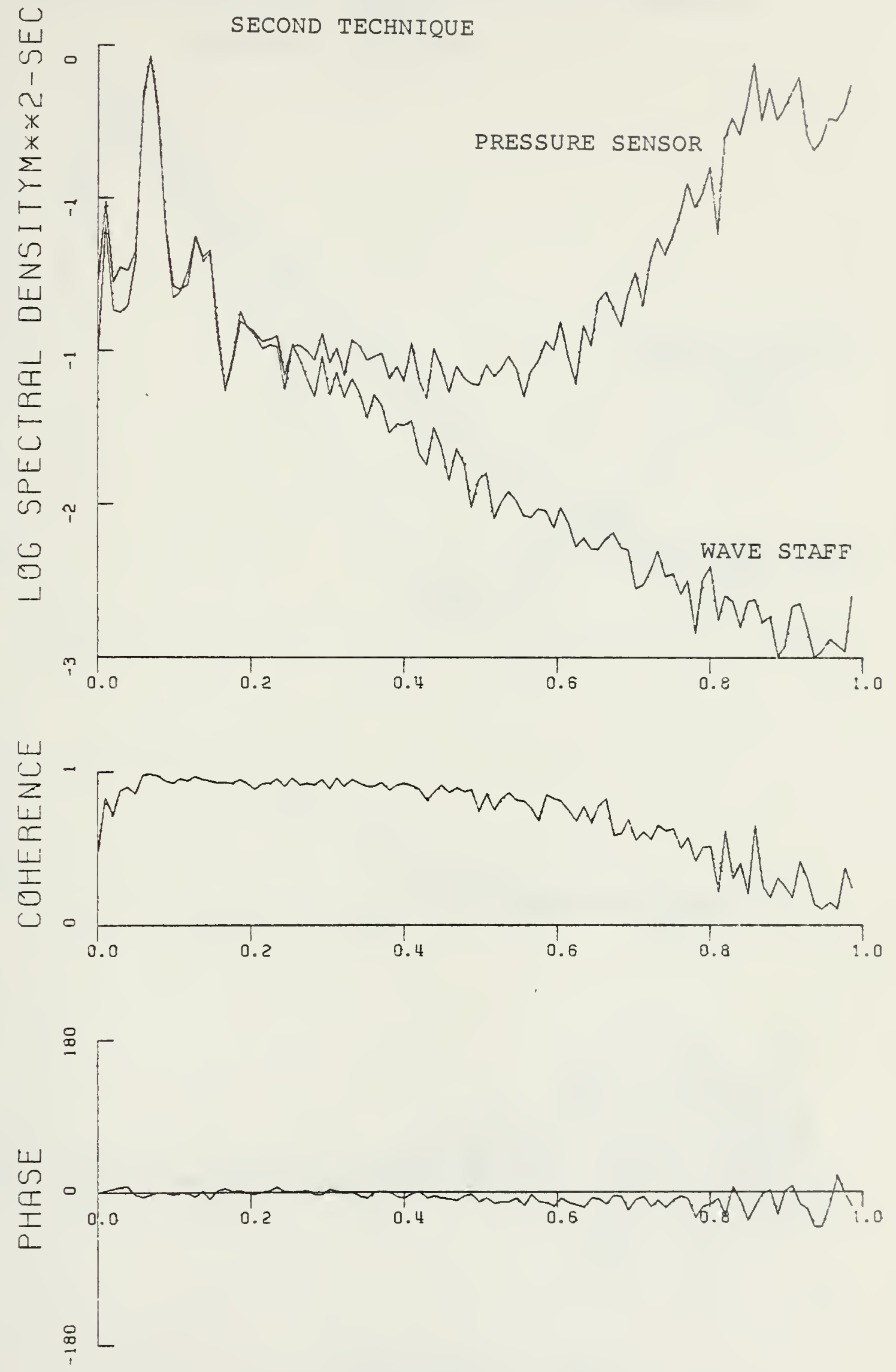

FREQUENCY (HZ) 

POWER, COHERENCE AND PHASE SPECTRA FOR 19 JULY MORNING
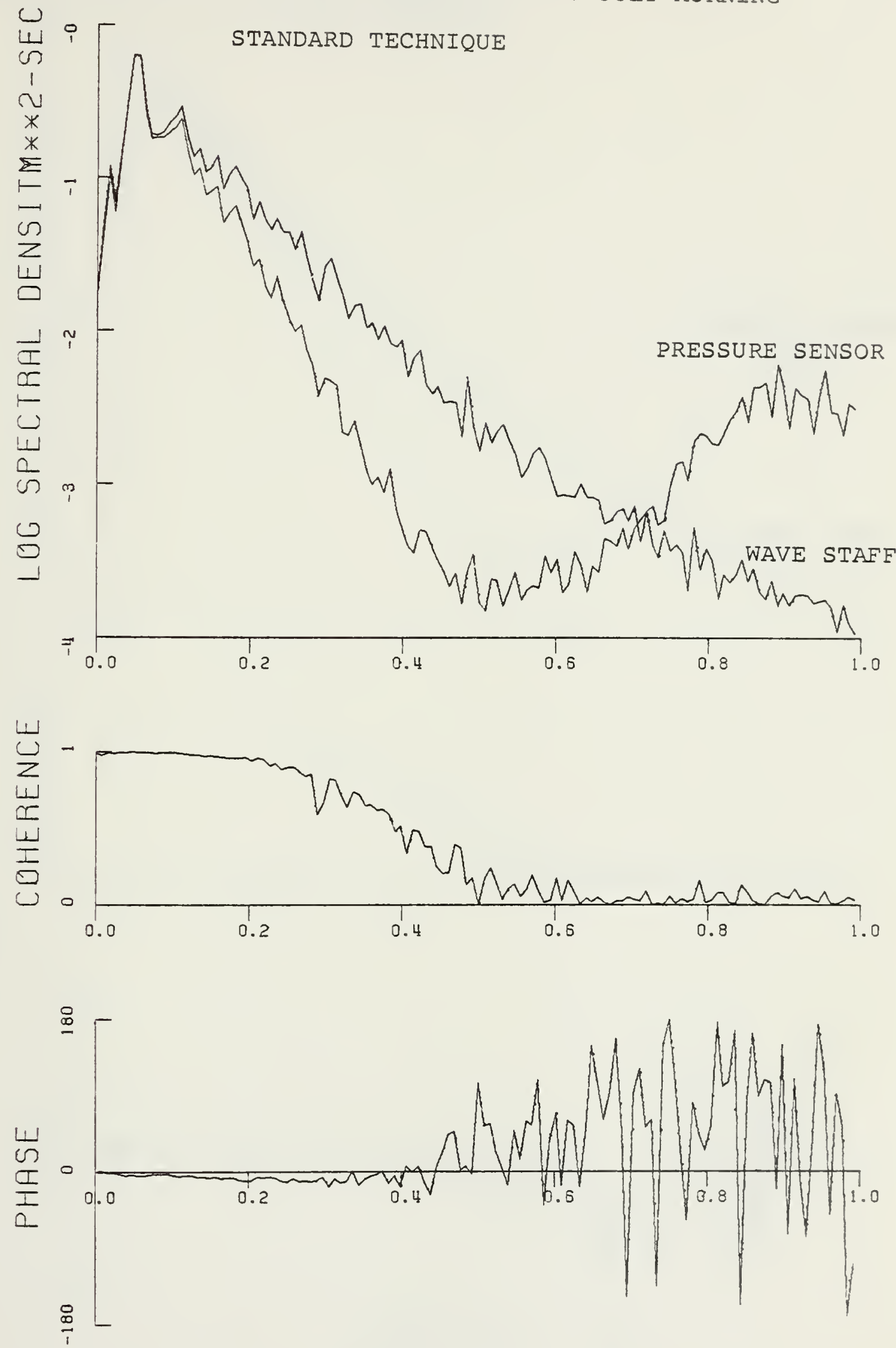

FREQUENCY (HZ) 

, POWER, COHERENCE AND PHASE SPECTRA FOR 19 JULY MORNING
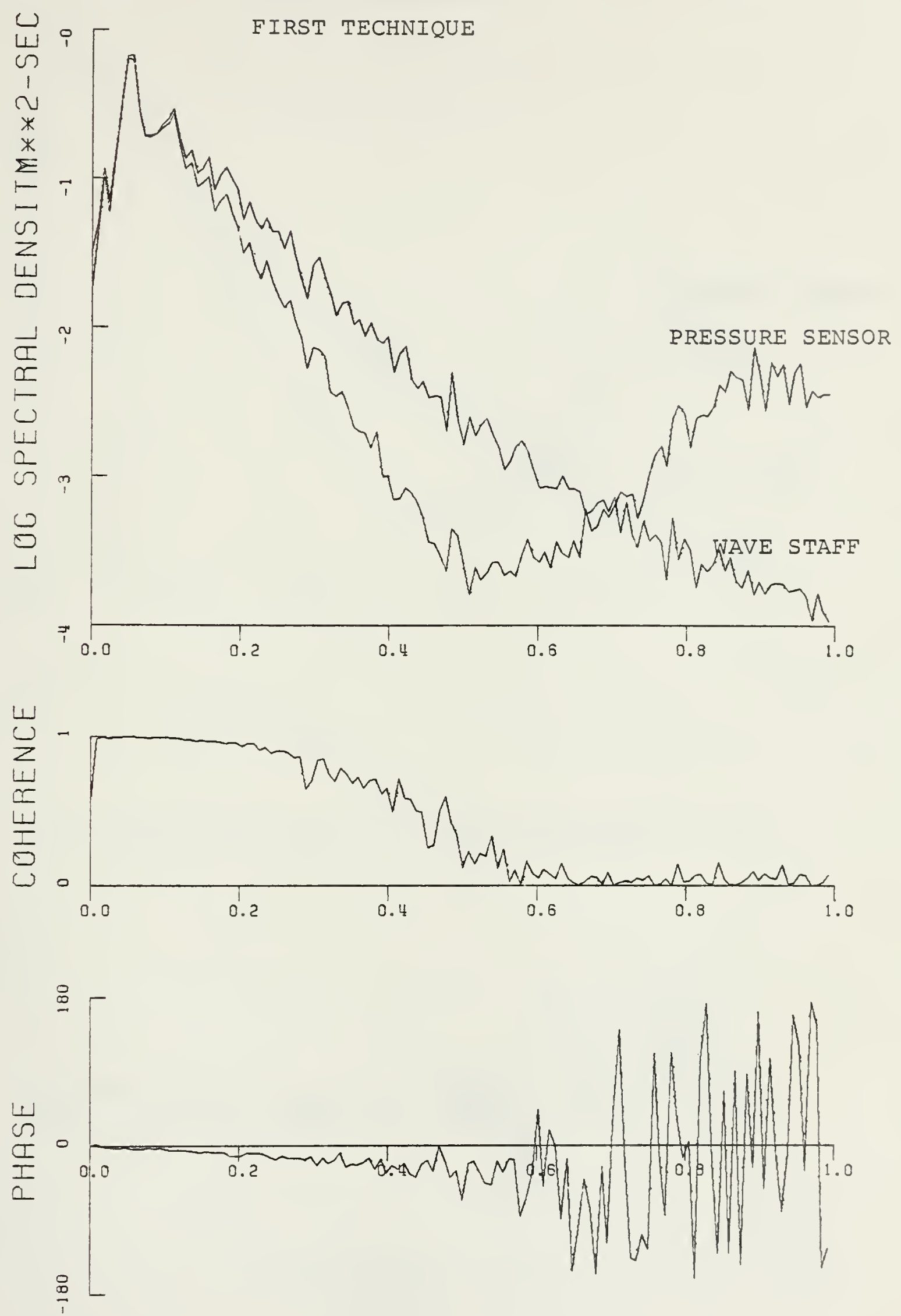

FREQUENCY (HZ) 

POWER, COHERENCE AND PHASE SPECTRA FOR 19 JULY MORNING

$\underset{\omega}{U}$ i S SECOND TECHNIQUE
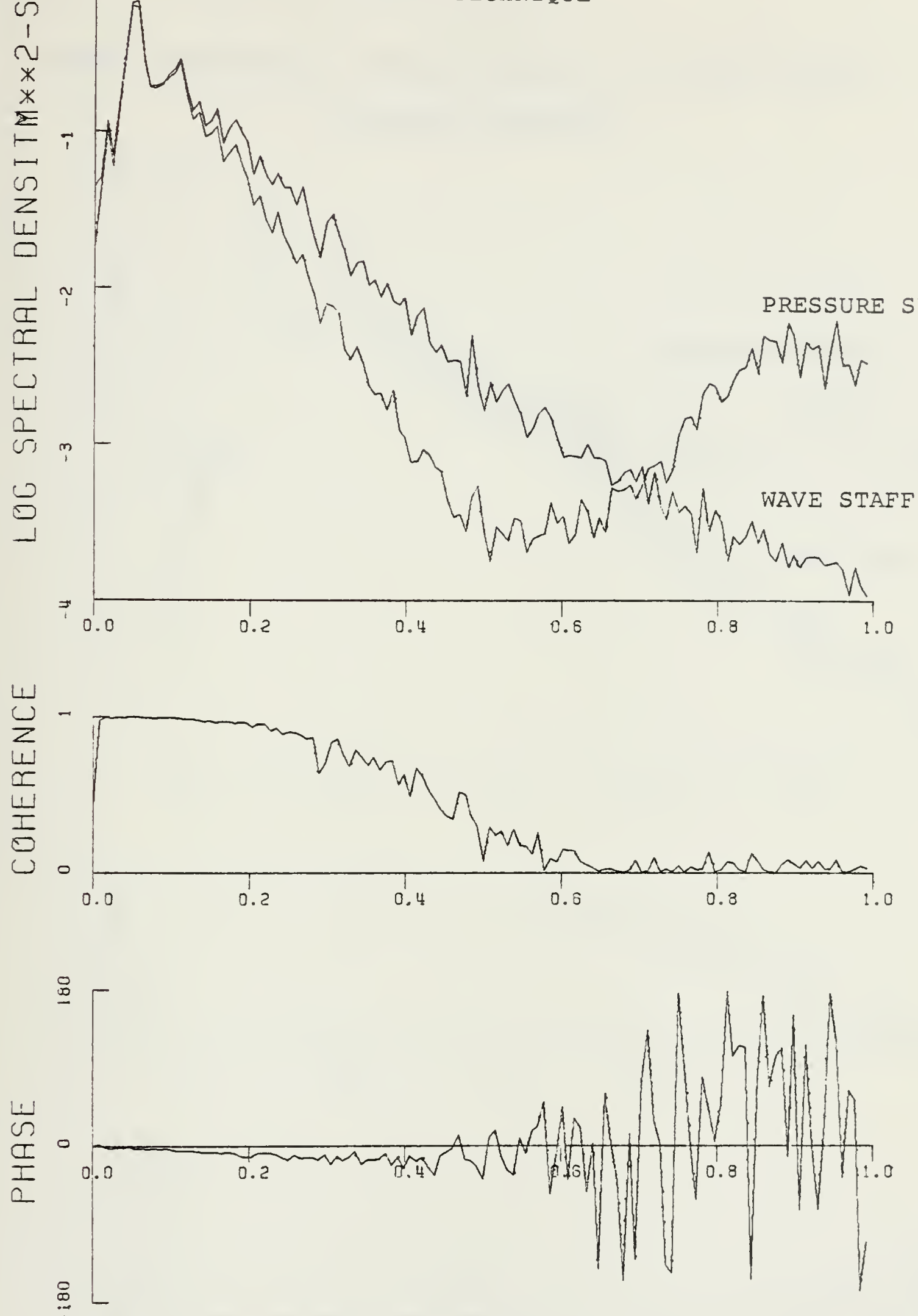

FREQUENCY $(H Z)$ 

POWER, COHERENCE AND PHASE SPECTRA FOR 20 JULY MORNING
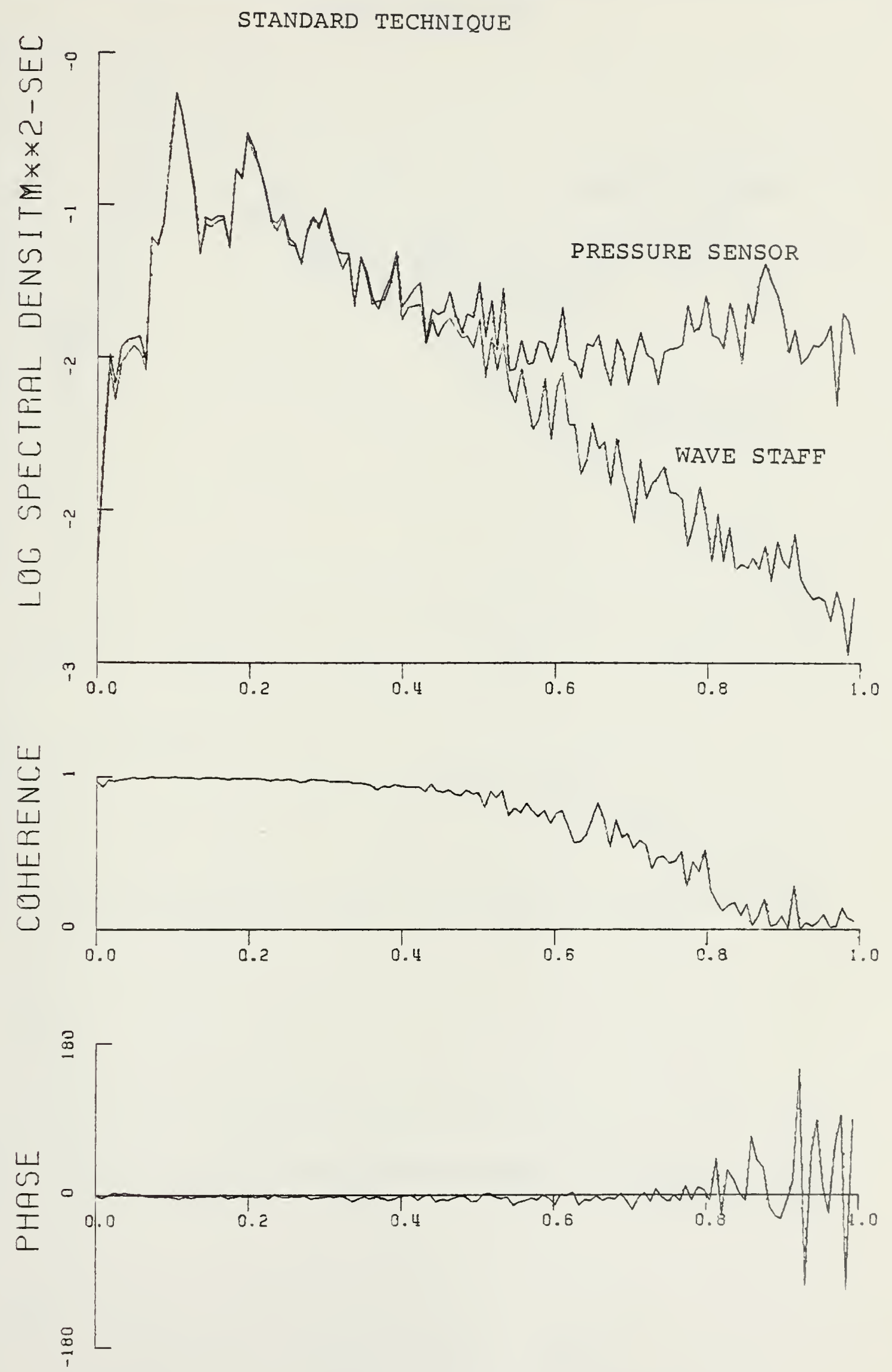

POWER, COHERENCE AND PHASE SPECTRA FOR 20 JULY MORNING
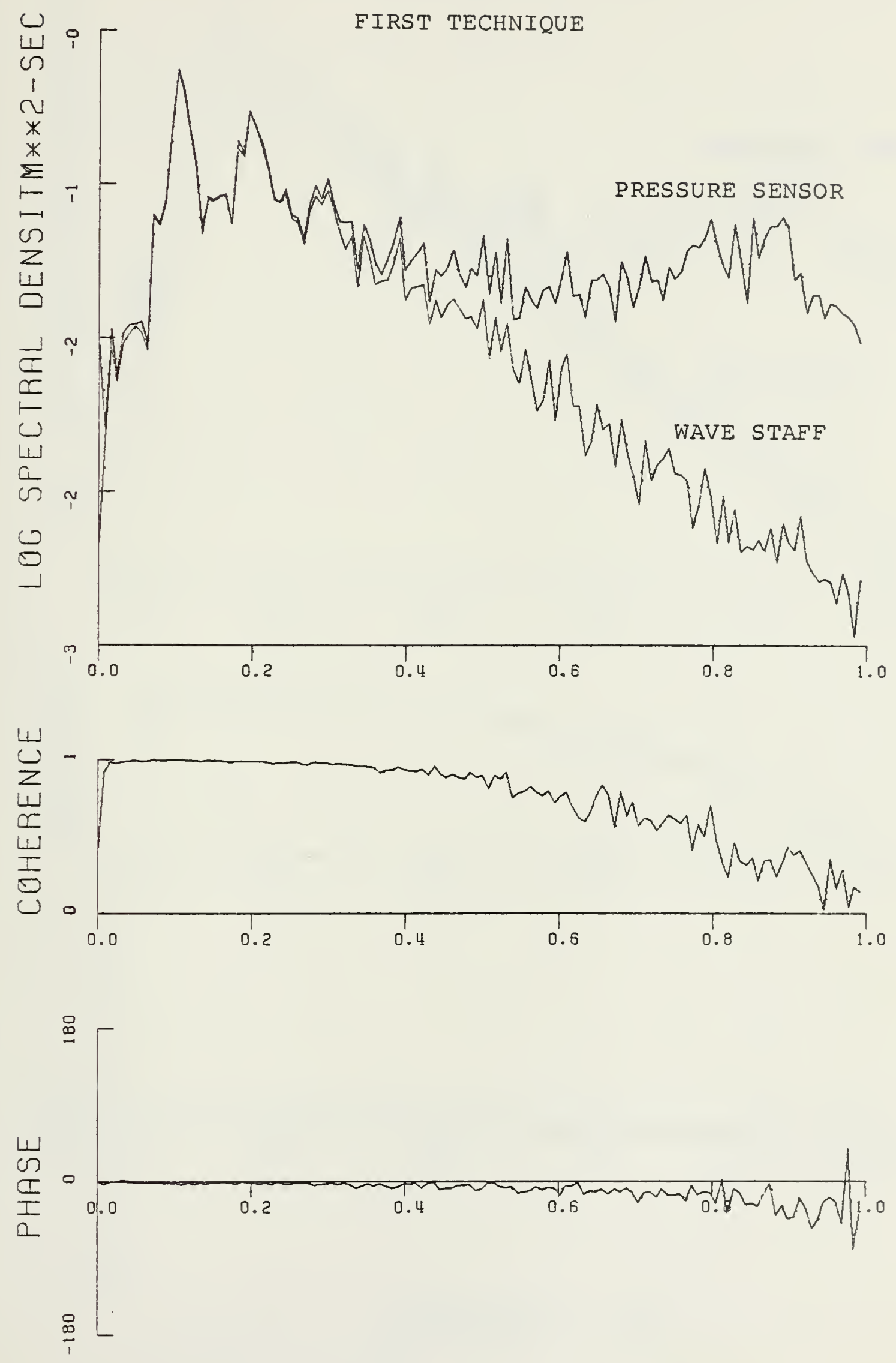

FREQUENCY (HZ) 

POWER, COHERENCE AND PHASE SPECTRA FOR 20 JULY MORNING
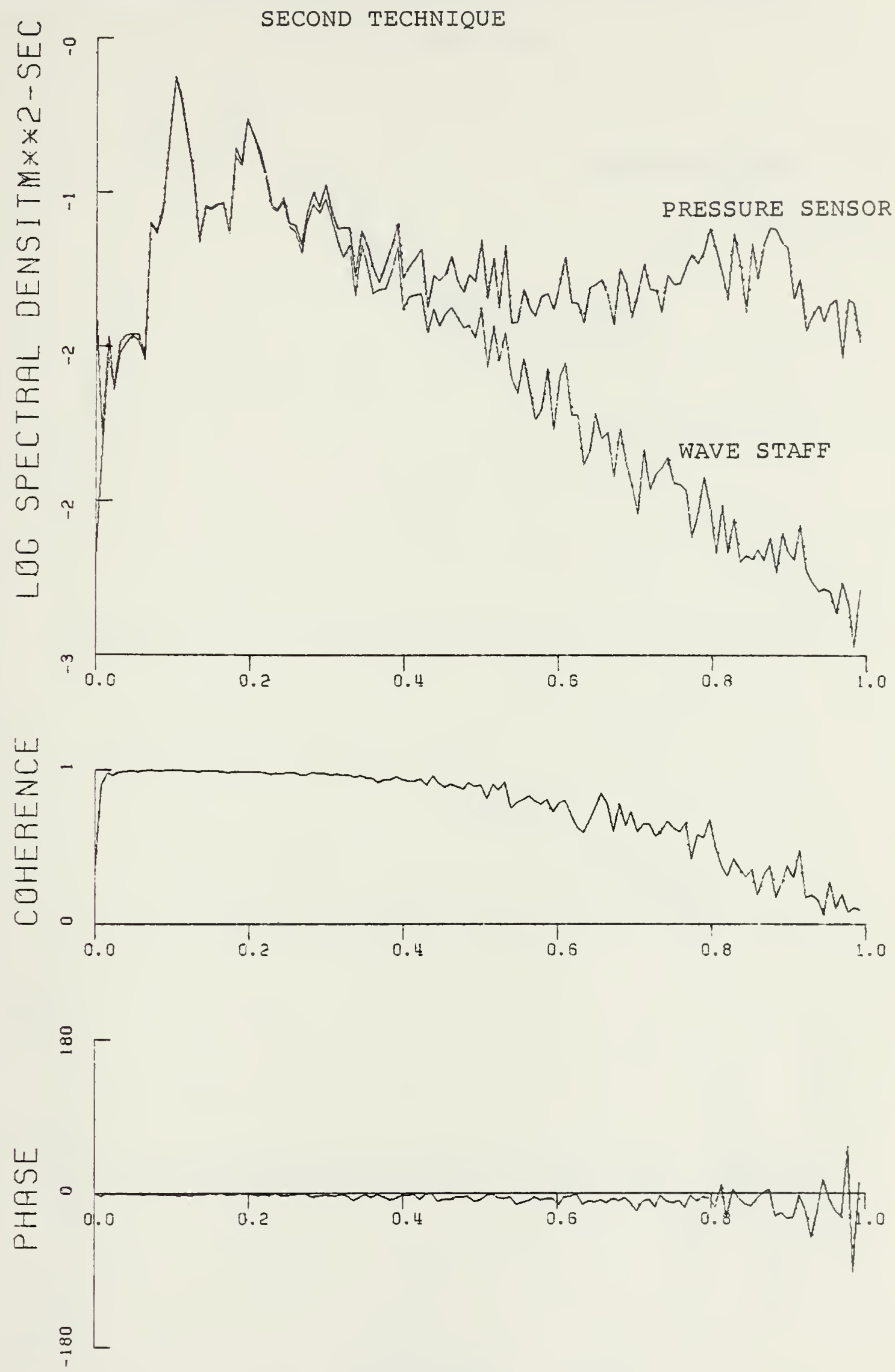

FREQUENCY (HZ) 

POWER, COHERENCE AND PHASE SPECTRA FOR 20 JULY EVENING
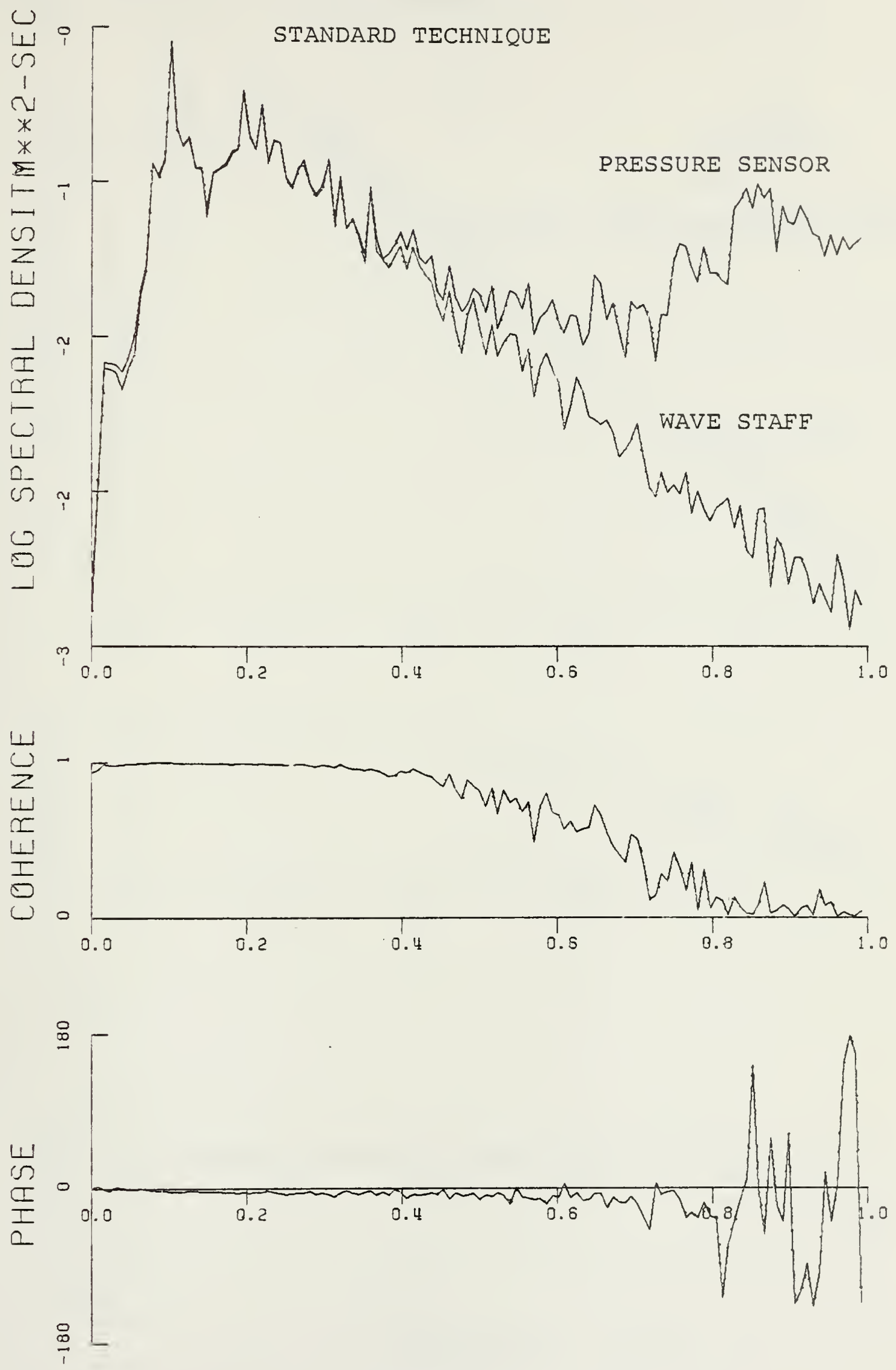

FREQUENCY (HZ) 

POWER, COHERENCE AND PHASE SPECTRA FOR 20 JULY EVENING
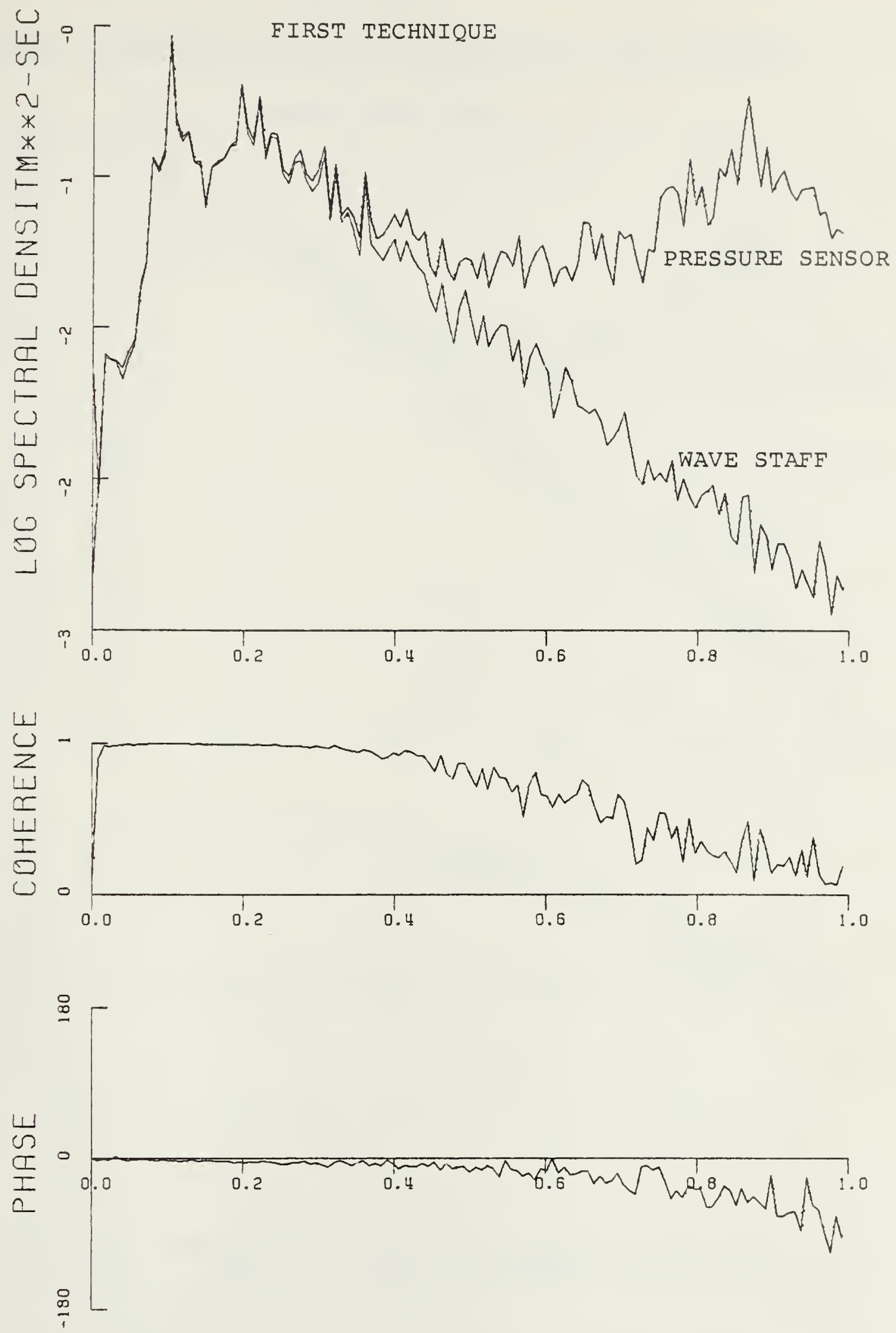

FREQUENCY (HZ) 

POWER, COHERENCE AND PHASE SPECTRA FOR 20 JULY EVENING
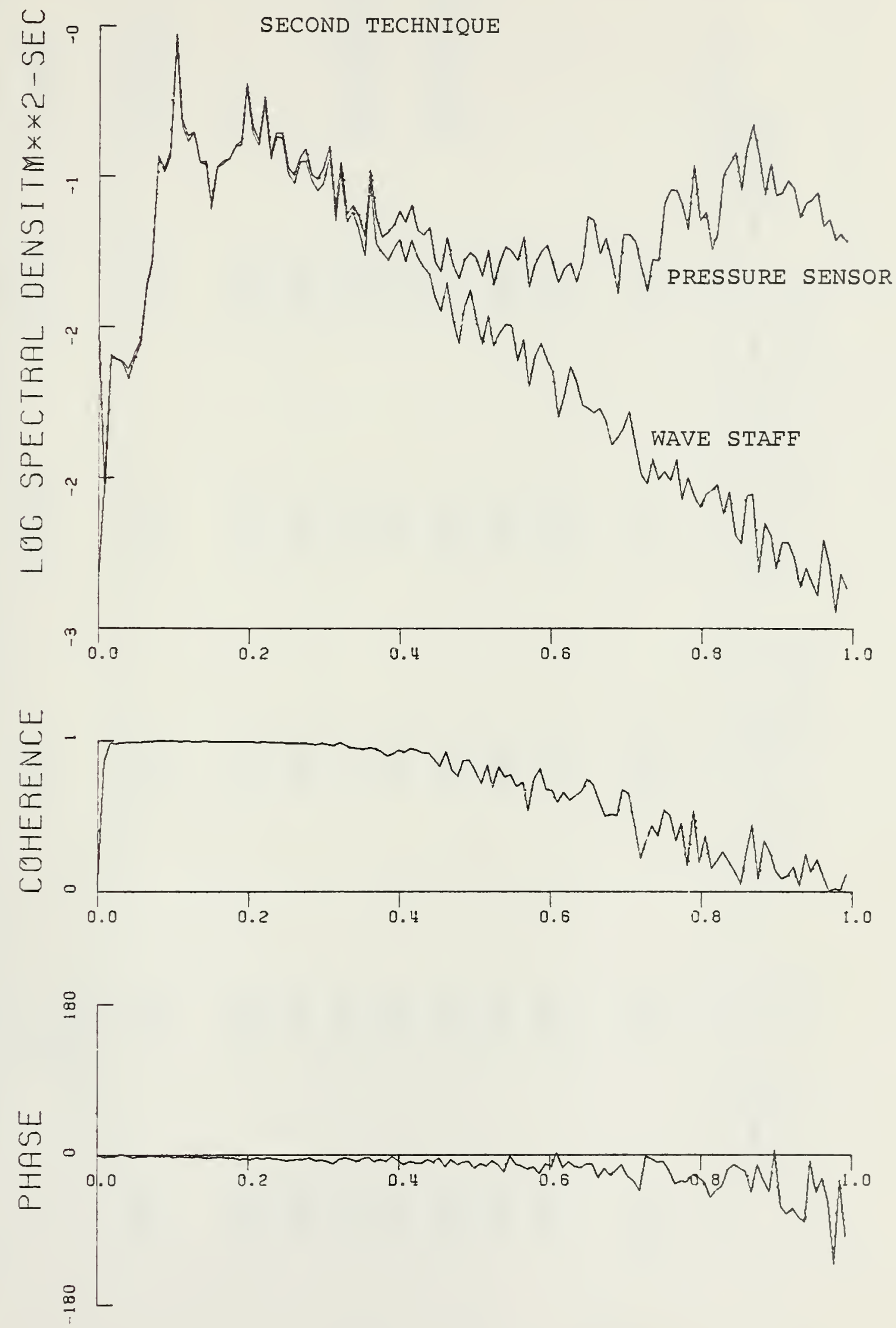

FREQUENCY (HZ) 

APPENDIX D

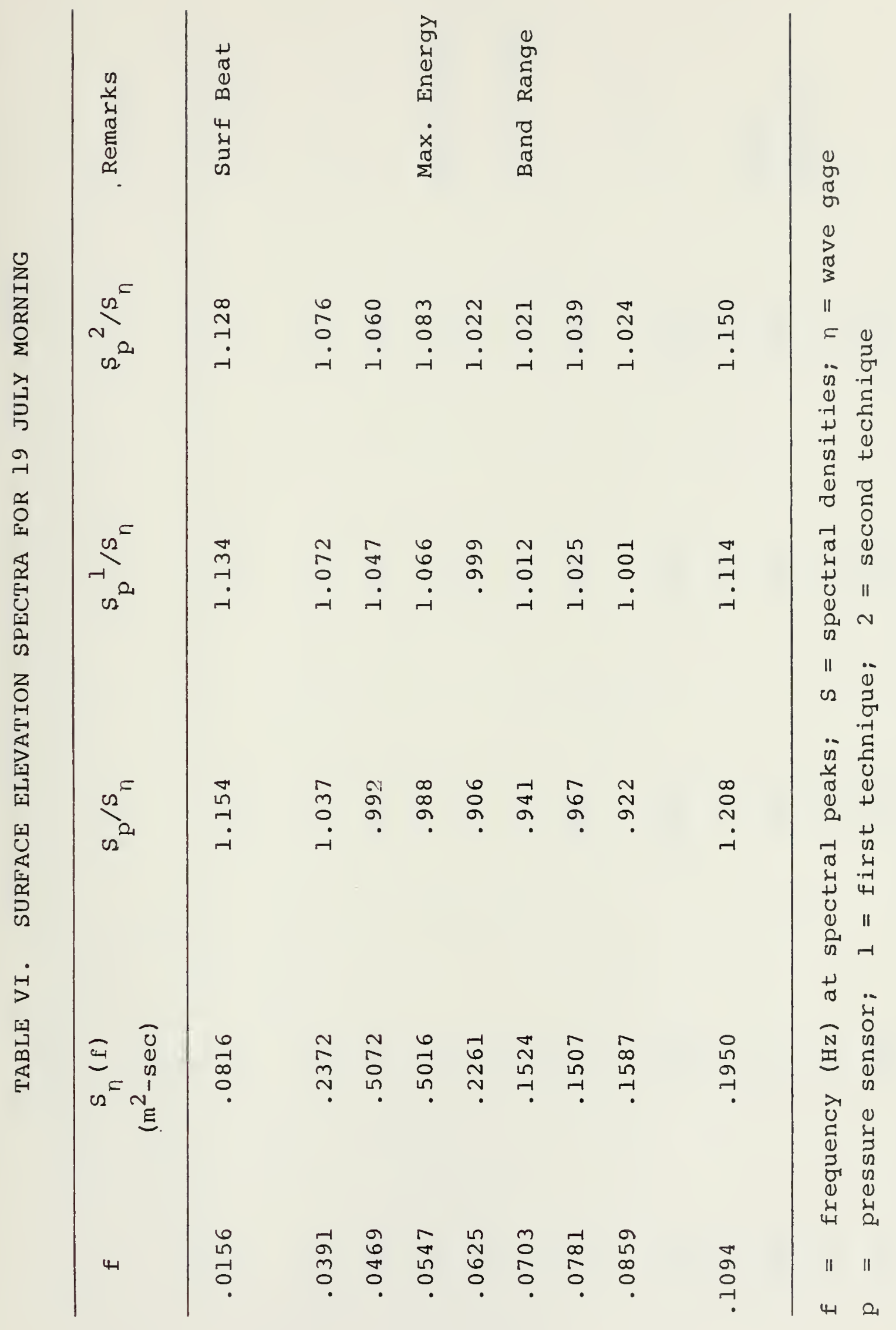





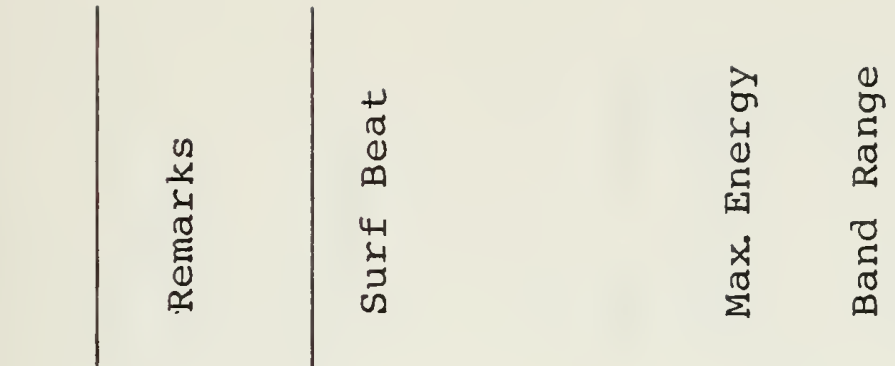

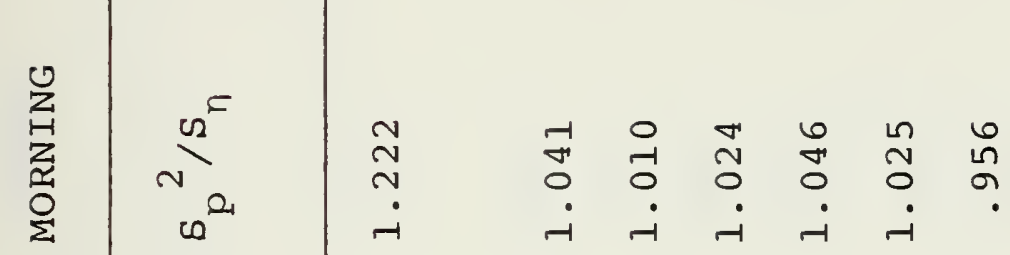

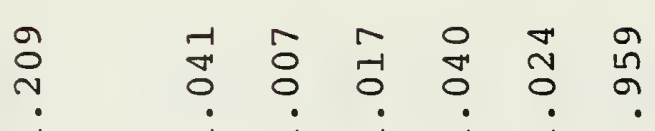

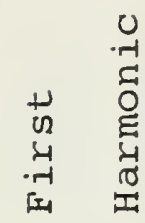

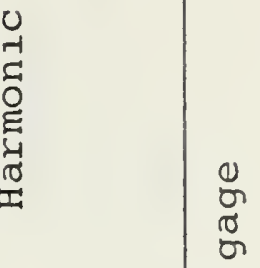

$$
\begin{aligned}
& \stackrel{0}{2}
\end{aligned}
$$

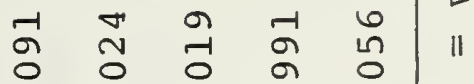

$$
\begin{aligned}
& \text { 零 } \\
& \text { ำ } \\
& \text { 范 } \\
& \text { 选 }
\end{aligned}
$$

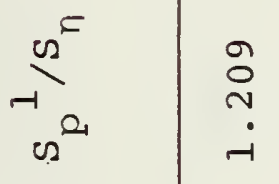

$$
\begin{aligned}
& \begin{array}{llllll}
-1 & -1 & -1 & -1
\end{array}
\end{aligned}
$$

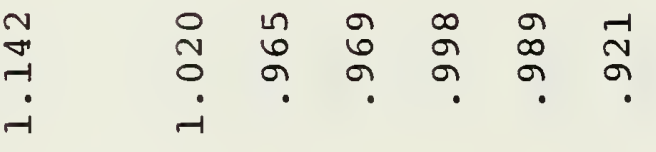

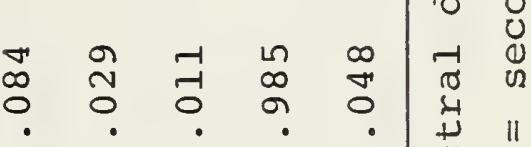

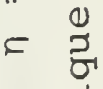

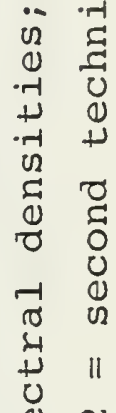

$$
\begin{aligned}
& \text { N } \\
& \text { 焦 }
\end{aligned}
$$

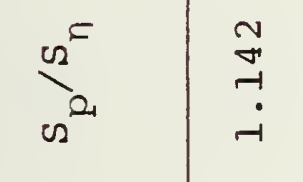

$$
\begin{aligned}
& \text { ॥ } \\
& \text { 吾 }
\end{aligned}
$$

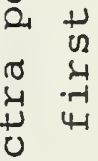

$$
\begin{aligned}
& \stackrel{\substack{-1 \\
>}}{-1} \\
& \text { 倠 }
\end{aligned}
$$

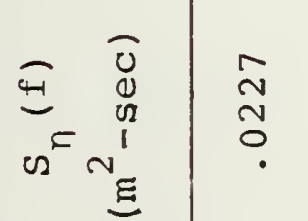

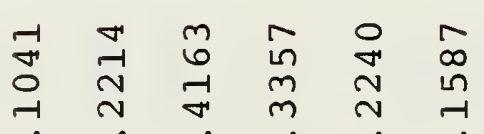

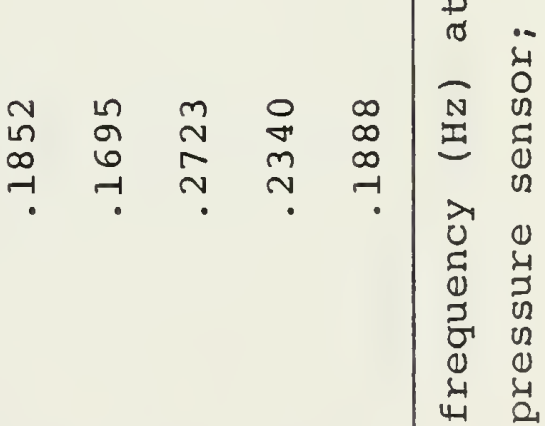

$$
\begin{aligned}
& \begin{array}{lll}
1 & 6 \\
4 & 0 \\
0 & 0
\end{array}
\end{aligned}
$$

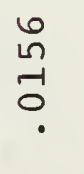

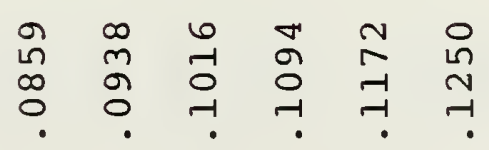

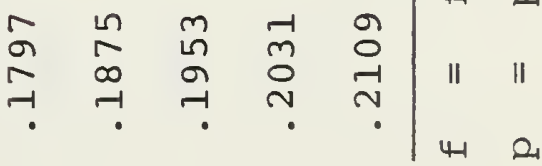





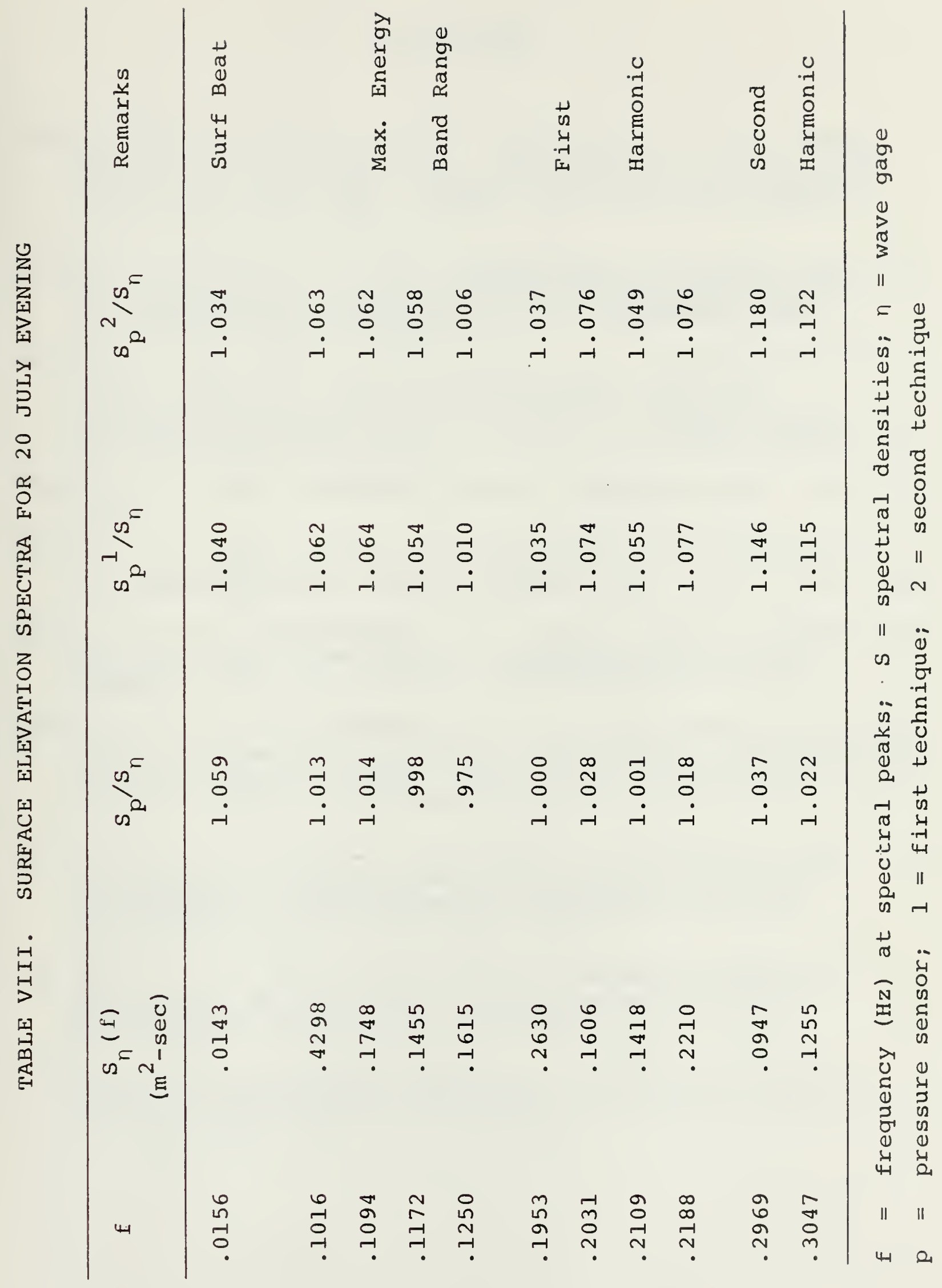





\section{BIBLIOGRAPHY}

Bowben, K. F. and White, R. A., "Measurements of the Orbital Velocities of Sea Waves and Their Use in Determining the

Directional Spectrum," Journal of Geophysical Research,

Vol 12, pp 33-54, 1966 .

Esteva, D. and Harris, D. L., "Comparison of Pressure and Staff Wave Gage Records," Proceedings of the Twelfth Coastal Engineering Conference, pp 101-116, September 1970.

Gerhardt, J. R., Jehn, K. H. and Katz, I., "A Comparison of Step-, Pressure-, and Continuous-Wire-Gage Wave

Recordings in the Golden Gate Channel," Transactions, American Geophysical Union, Vol 36, pp 235-250, April 1955.

Grace, R. A., "How to Measure Waves," Ocean Industry, pp 65-69, 1970 .

Kinsman, B., "Wind Waves, Their Generation and Propagation on The Ocean Surface," Prentice-Hall, Inc., pp 133-144, 1965.

Thornton, E. B. and Krapohl, R. F., "Water Particle Velocities Measured Under Ocean Waves," Journal of Geophysical Research, Vol 79, pp 847-852, 20 Feb 1974.

Thornton, E. B. and Richardson, D. P., "The Kinematics of Wave Particle Velocities of Breaking Waves Within the Surf Zone," Technical Report NPS-58T 74011A, Naval Postgraduate School, Monterey, California, January 1974.

Thornton, E. B., Galvin, J. J., Bub, F. L. and Richardson, D. P., "Kinematics of Breaking Waves Within the Surf Zone," Proceedings of the Fifteenth Conference on Coastal Engineering, pp 461-476, ASCE, 1976.

Van Dorn, W. G., "Set-up and Run-up in Shoaling Breakers," Prodeedings of the Fifteenth Conference on Coastal Engineering, pp 738-751, July 1976.

Van Dorn, W. G., "Breaking Invariants in Shoaling Waves," Journal of Geophysical Research, Vol 83, No C6, pp 29812988, 20 June 1978. 

No. Copies

1. Defense Documentation Center

Cameron Station

Alexandria, Virginia 22314

2. Library, Code 0142

Naval Postgraduate School

Monterey, California 93940

3. Department Chairman, Code 68

Department of oceanography

Naval Postgraduate school

Monterey, California 93940

4. Associate Professor E. B. Thornton, code $68 \mathrm{Tm} 5$ Department of Oceanography

Naval Postgraduate School

Monterey, California 93940

5. IT Vitor Goncalo

Instituto Hidrografico, Rua das Trinas

Lisbon, PORTUGAL

6. Oceanographer of the Navy

Hoffman Building No. 2

200 Stovall street

Alexandria, Virginia 22332

7. Office of Naval Research

Code 410

NORDA

NSTS, Station, MS 39529

8. Dr. Robert E. Stevenson

Scientific Liaison Office, ONR

5

Scripps Institution of Oceanography

La Jolla, CA 92037

9. Library, Code 3330

Naval Oceanographic Office

Washington, D. C. 20373

10. SIO Library

University of California, San Diego

P. O. Box 2367

La Jolla, California 92037 

11. Department of Oceanography Library

University of Washington

Seattle, WA 98105

12. Department of Oceanography Library

Oregon State University

Corvallis, Oregon 97331

13. Director

Naval Oceanography and Meteorology

National Space Technology Laboratories

NSTL Station, MS 39529

14. NORDA

NSTL Station, MS 39529

15. Commanding officer

Fleet Numerical Weather Central

Monterey, CA 93940

16. Commanding officer

Naval Environmental Prediction Research Facility Monterey, CA 93940

17. Department of the Navy

1

Commander Oceanographic System Pacific

Box 1390

FPO San Francisco 96610

18. Departamento de Oceanografia

Instituto Hidrografico

Rua das Trinas, Lisbon, PORTUGAL

19. Direccao do Servico de Instrucao

Ministerio da Marinha

Praca do Comercio, Lisbon, PORTUGAL 



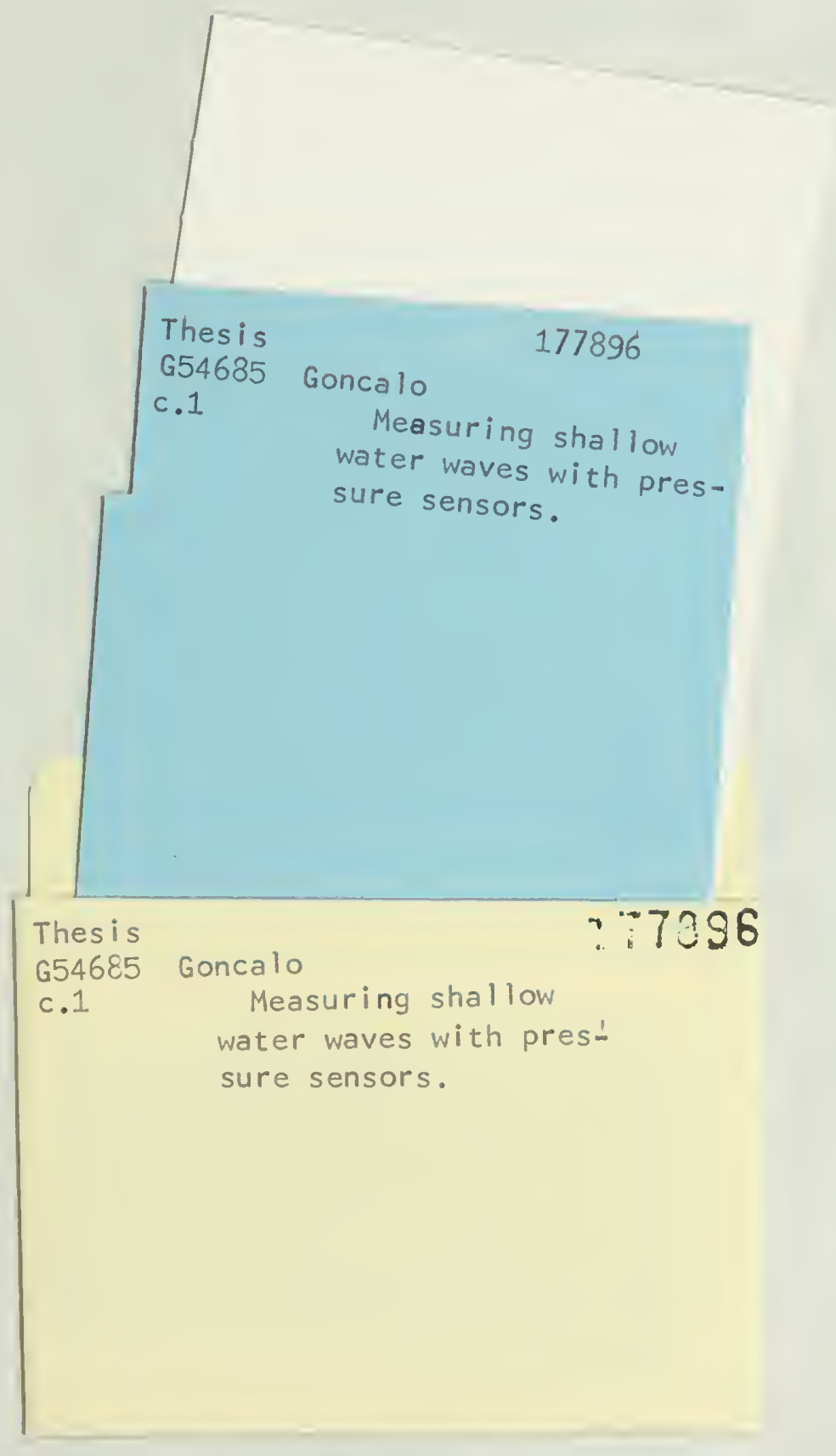


thesG54685

Measuring shallow water waves with press

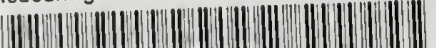

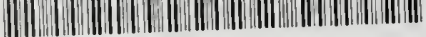

32768002130817

DUDLEY KNOX LIBRARY 